\title{
Light Water Reactor Sustainability Program
}

\section{Flooding Fragility Experiments and Prediction}

Curtis L Smith, Bishwo Bhandari, Cody Muchmore, Antonio Tahhan, Alison Wells, Larinda Nichols, Chad Pope

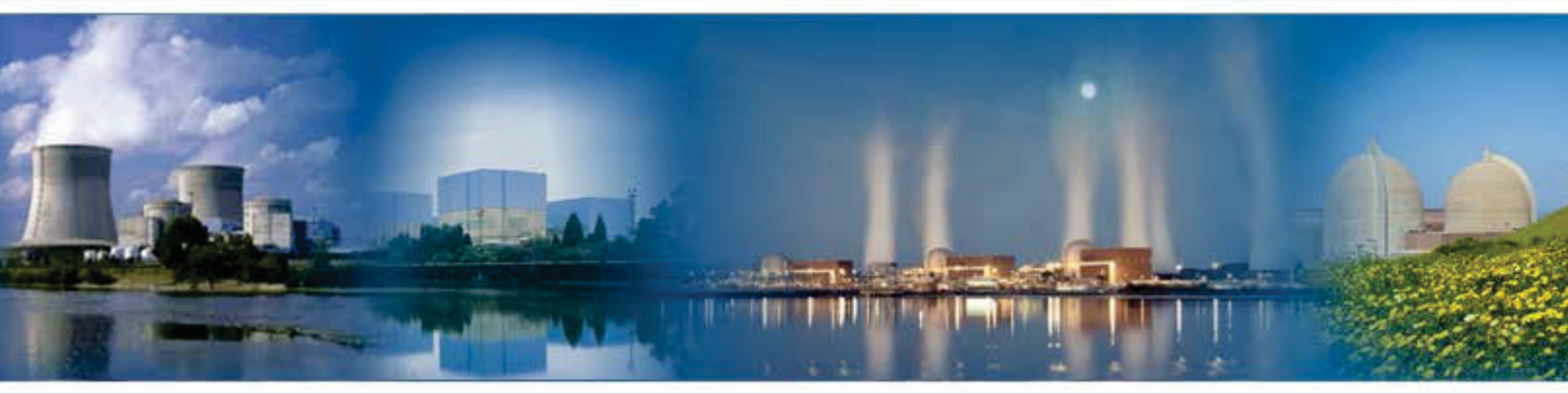

September 2016

DOE Office of Nuclear Energy 


\section{DISCLAIMER}

This information was prepared as an account of work sponsored by an agency of the U.S. Government. Neither the U.S. Government nor any agency thereof, nor any of their employees, makes any warranty, expressed or implied, or assumes any legal liability or responsibility for the accuracy, completeness, or usefulness, of any information, apparatus, product, or process disclosed, or represents that its use would not infringe privately owned rights. References herein to any specific commercial product, process, or service by trade name, trade mark, manufacturer, or otherwise, does not necessarily constitute or imply its endorsement, recommendation, or favoring by the U.S. Government or any agency thereof. The views and opinions of authors expressed herein do not necessarily state or reflect those of the U.S. Government or any agency thereof. 


\title{
Light Water Reactor Sustainability Program
}

\section{Flooding Fragility Experiments and Prediction}

\author{
Curtis L Smith - INL \\ Bishwo Bhandari - Idaho State University \\ Cody Muchmore - Idaho State University \\ Antonio Tahhan - Idaho State University \\ Alison Wells - Idaho State University \\ Larinda Nichols - Idaho State University \\ Chad Pope - Idaho State University
}

September 2016

Idaho National Laboratory

Idaho Falls, Idaho 83415

http://www.inl.gov/lwrs

Prepared for the

U.S. Department of Energy

Office of Nuclear Energy

Under DOE Idaho Operations Office

Contract DE-AC07-05ID14517 



\begin{abstract}
This report describes the work that has been performed on flooding fragility, both the experimental tests being carried out and the probabilistic fragility predictive models being produced in order to use the test results. Flooding experiments involving full-scale doors have commenced in the Portal Evaluation Tank. The goal of these experiments is to develop a full-scale component flooding experiment protocol and to acquire data that can be used to create Bayesian regression models representing the fragility of these components. This work is in support of the Risk-Informed Safety Margin Characterization (RISMC) Pathway external hazards evaluation research and development.
\end{abstract}




\section{CONTENTS}

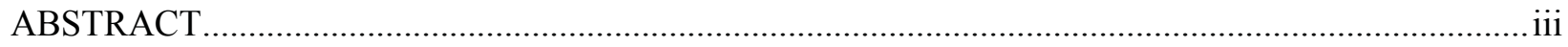

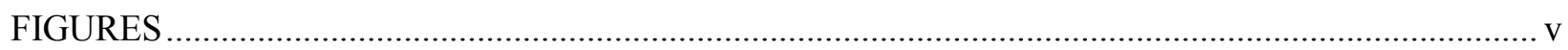

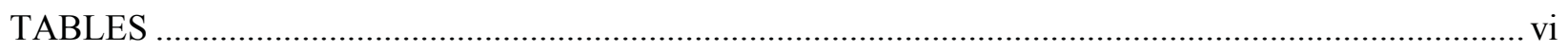

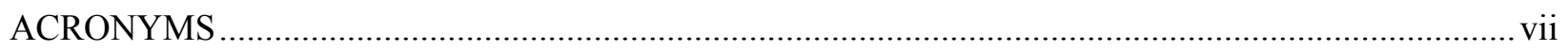

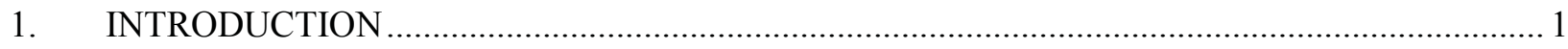

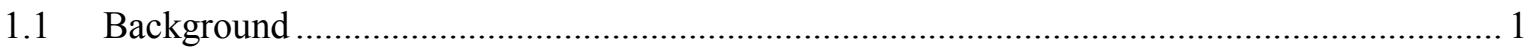

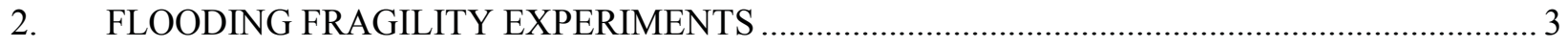

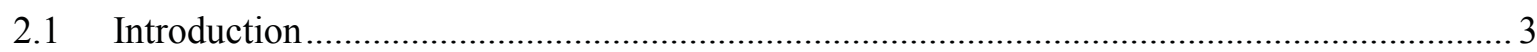

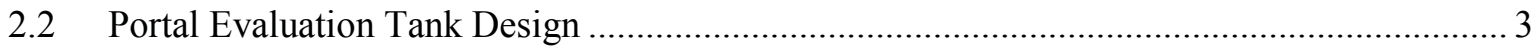

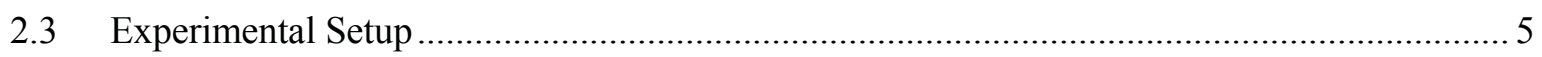

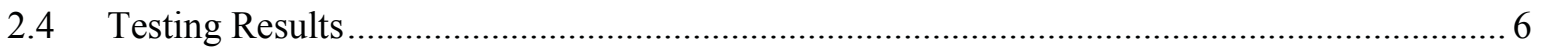

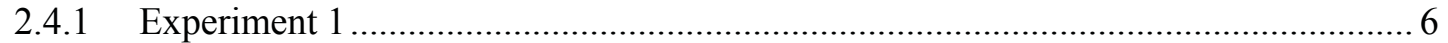

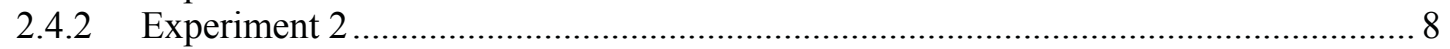

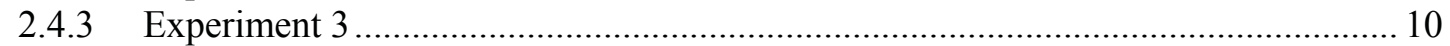

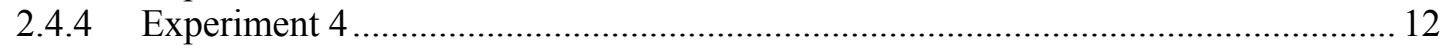

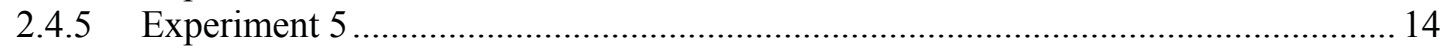

2.5 Flooding Fragility Experiments Conclusions.......................................................... 17

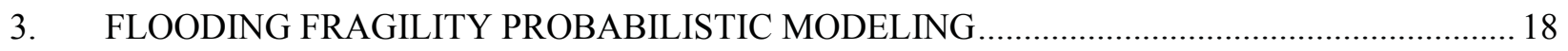

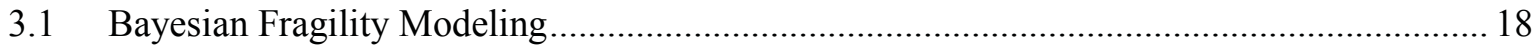

3.2 Example of a Bayesian Regression Model......................................................................... 19

3.3 Example of a Flooding Bayesian Regression Model ........................................................ 22

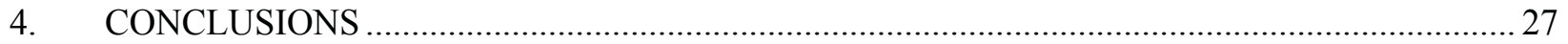

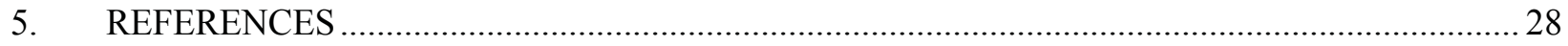




\section{FIGURES}

Figure 1. Overview of RISMC simulation approach for a tsunami and plant response............................. 1

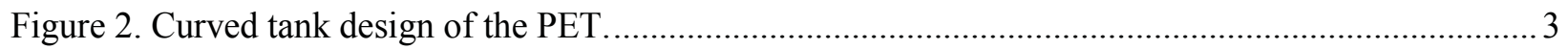

Figure 3. General arrangement of the PET pump, piping and flow directing valves................................. 4

Figure 4. Piping, flow controls valves, and flow meter arrangement. ................................................. 5

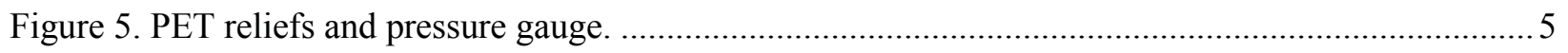

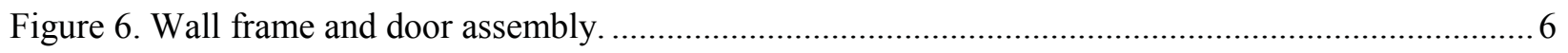

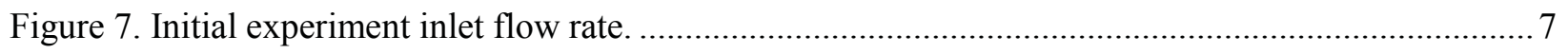

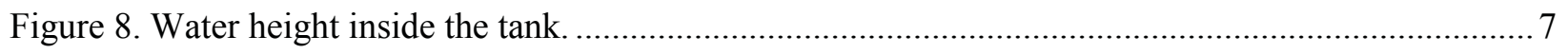

Figure 9. Experiment 1 door latch engagement area failure ................................................................ 8

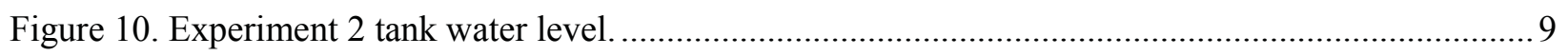

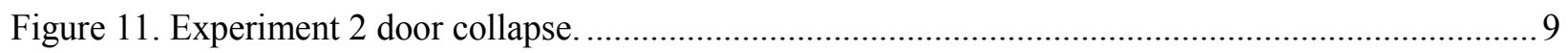

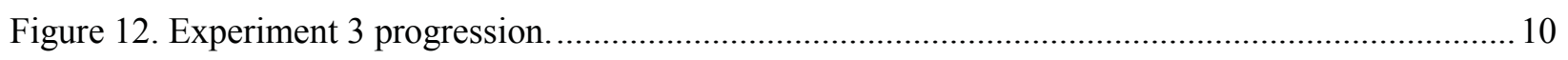

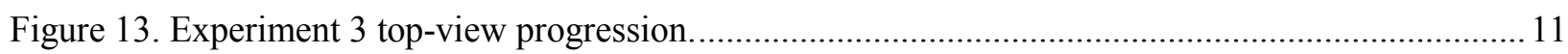

Figure 14. Experiment 3 Inlet flow rate, tank fill rate, and leakage rate.............................................. 11

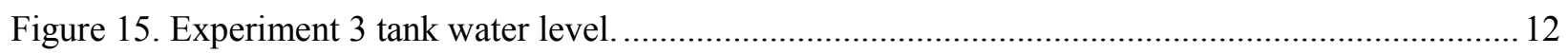

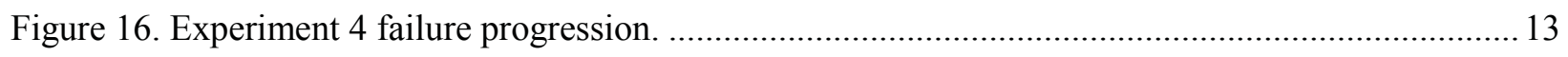

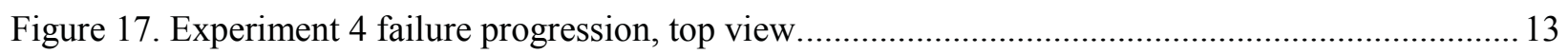

Figure 18. Experiment 4 inlet flow, fill rate, and leakage rate............................................................... 14

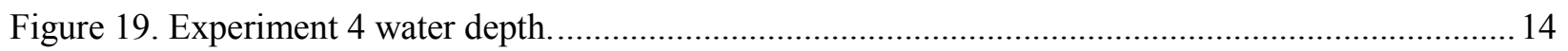

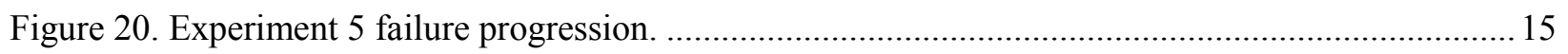

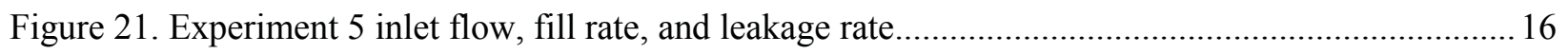

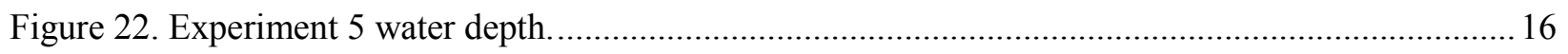

Figure 23. Illustration of seismic fragility model for an example component........................................ 18

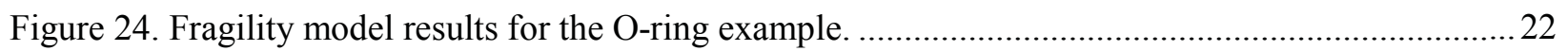

Figure 25. Illustration of the type of information collected during flooding fragility testing...................23

Figure 26. Example of possible influencing factors that may affect component flooding fragility............24

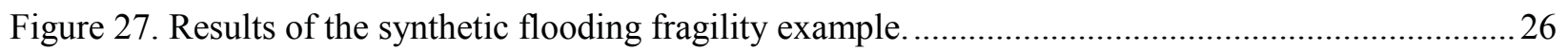




\section{TABLES}

Table 1. O-ring thermal stress data prior to launch of Challenger in January 1986. ................................ 19

Table 2. OpenBUGS script for regression model for the O-ring fragility example................................20

Table 3. Parameter results (mean values) of the O-ring fragility regression models...............................21

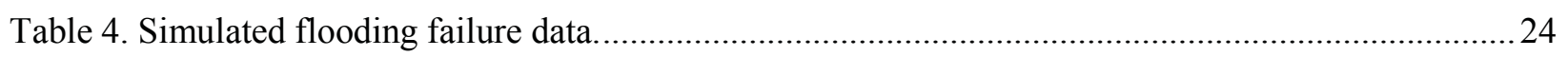

Table 5. OpenBUGS script for flooding fragility model for the synthetic example ................................25

Table 6. Parameter results (mean values) of the fragility model for the synthetic example.....................26 


\section{ACRONYMS}

CFEL component flooding evaluation laboratory

ISU Idaho State University

NPP nuclear power plant

PET portal evaluation tank

RISMC Risk-Informed Safety Margin Characterization 


\section{Flooding Fragility Experiments and Prediction 1. INTRODUCTION}

\subsection{Background}

In the Risk-Informed Safety Margin Characterization (RISMC) Pathway, an important part of the research being investigated is related to flooding hazards. These hazards take on two types, external (where water enters the plant site external to the plant, for example via a tsunami or river flood) or internal (where water inside the plant impacts structures or components in an off-normal condition, for example following a pipe break). In either case, one of the questions of interest in the flooding-scenario modeling is that of how susceptible to failure structures and components are to the water ingress or spray. This question is characterized by the structure or component "flooding fragility."

The purpose of this report is to describe the progress in RISMC flooding fragility experiments and associated probabilistic fragility modeling. The RISMC Pathway has extended its analysis capabilities for the flooding hazard approach by using five risk analysis steps, illustrated for tsunami modeling in Figure 1:

1. Initiating event modeling: modeling characteristic parameters and associated probabilistic distributions of the seismic or flooding event

2. Plant response modeling: modeling of the plant system dynamics

3. Components failure modeling: modeling of specific components/systems that may stochastically change status due to the initiating event or other external/internal causes

4. Scenario simulation: when all modeling aspects are complete, a set of simulations can be run by sampling the set of uncertain parameters.

5. Given the simulation runs generated in Step 4, a set of statistical information (e.g., extend of plant damage, safety margin, component importance) can be generated.

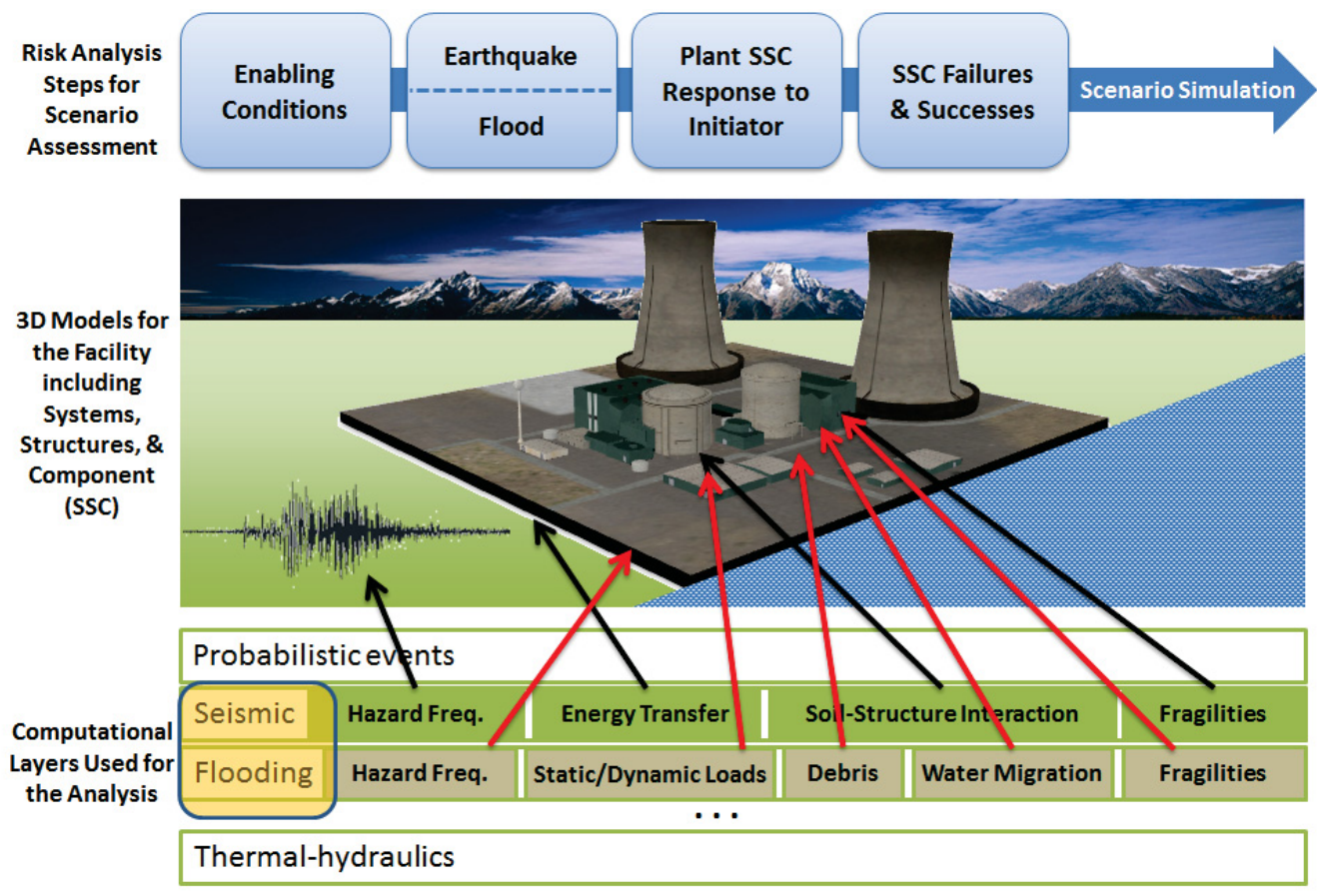

Figure 1. Overview of RISMC simulation approach for a tsunami and plant response. 
It is within steps 2 - 4 above that the flooding fragility modeling is realized. The remainder of this report is captured into two sections, Chapter 2 describing the experimental flooding fragility experiments and then Chapter 3 describing the flooding fragility probabilistic modeling. 


\section{FLOODING FRAGILITY EXPERIMENTS \\ 2.1 Introduction}

Flooding fragility experiments involving full-scale doors have commenced in the Portal Evaluation Tank (PET). The goal of these experiments is to develop a full-scale component flooding experiment protocol and to acquire data that can be used to create Bayesian regression models representing the component fragility. Results from the full-scale door experiments will inform future experiments in the PET with representative nuclear power plant (NPP) components as well as influencing the design of the Component Flooding Evaluation Laboratory (CFEL). The PET has the capability to test doors and penetrations of many different types and sizes, as well as electrical and ventilation wall feed-throughs and other small mechanical components. Additionally, the PET provides a testing space to evaluate things such a piping ruptures. The following sections describe the basic design of the PET, the experiments performed thus far, and initial results.

\subsection{Portal Evaluation Tank Design}

The PET was designed with a curved shape to minimize corner joints requiring welding. The semi-circular shape of the tank has a radius of $4 \mathrm{ft}$. with an 18-inch-long rectangular section on the downstream side (the front side), as shown in Figure 2. For safety enhancement, sections of the PET are supported with box beams to prevent tank flexing under pressure. The box beams at the bottom of the tank are 4 inches high, 6 inches wide, and 0.1875 inches thick. The curved tank design also includes a V-notch weir on the downstream side to measure the flow rate of water leakage. A general layout of the apparatus set-up is provided in Figure 3 showing the tank connected to a pump using 3-inch PVC piping.

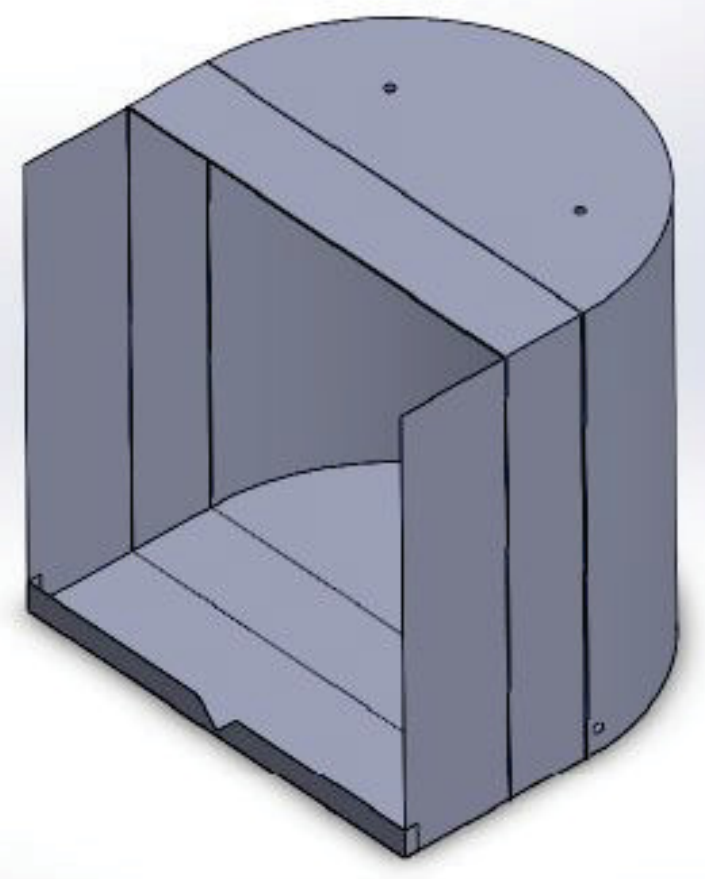

Figure 2. Curved tank design of the PET. 


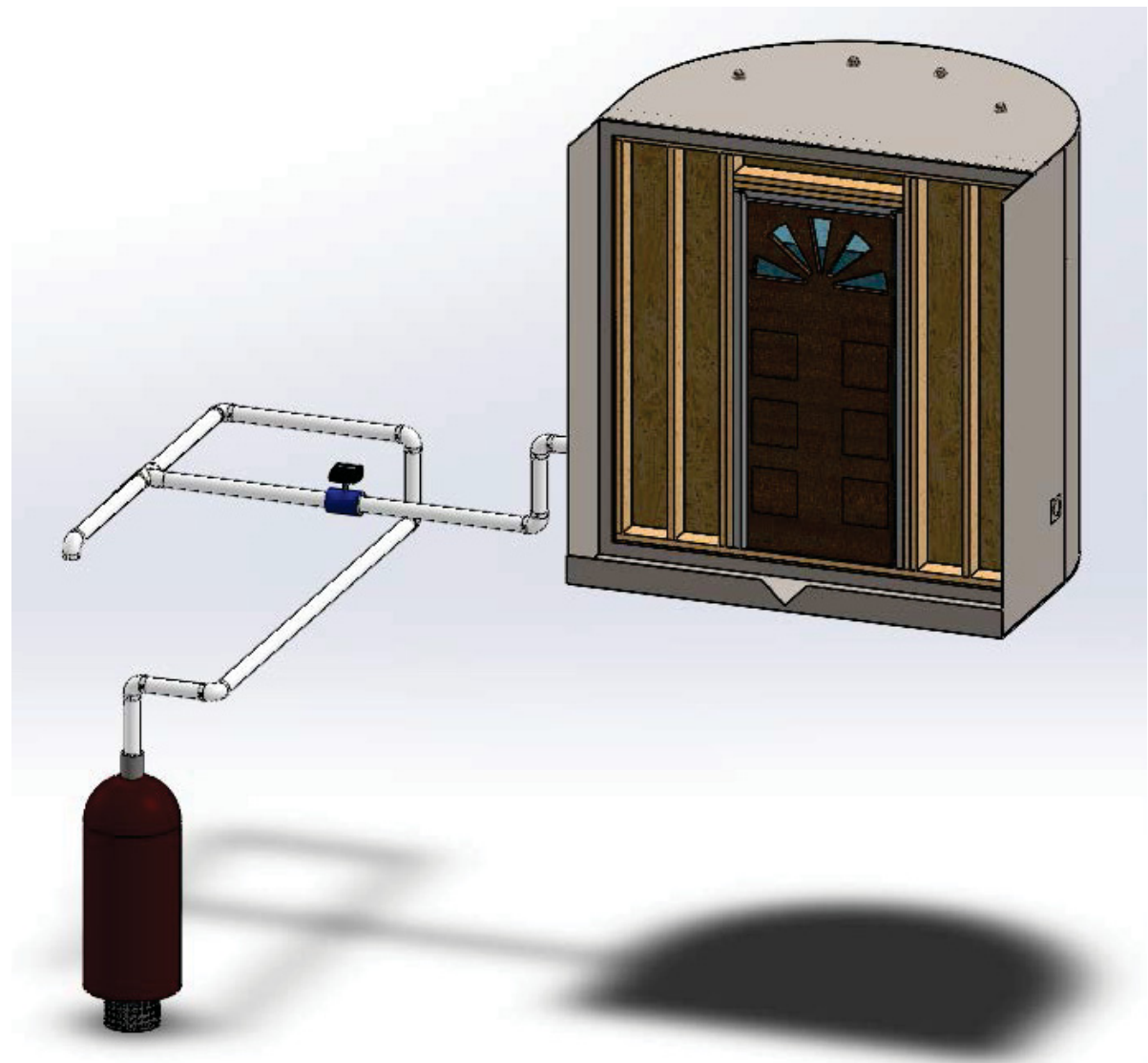

Figure 3. General arrangement of the PET pump, piping and flow directing valves.

Full-scale door experiments measure three parameters: leakage, water depth in the tank, and inlet flow rate. A pressure transducer was used to measure the level of water inside the tank, an ultrasonic level sensor was used to measure the depth of water at the $\mathrm{V}$-notch (leakage), and a flow meter was used to measure the flow rate of water into the tank. The PET is also equipped to measure the pressure inside the tank to allow future experiments where the pressure simulates water depths greater than the tank height.

A submersible pump was used to supply the water to the tank from an existing 8000-gallon reservoir. 3-inch PVC piping was used to connect the pump to the tank. Five $90^{\circ}$ elbows, one T-junction, and two ball valves were used in the piping section, as shown in Figure 4. The sacks of concrete mix shown in Figure 4 support the piping arrangement as well as stabilize the piping during pump transients. One ball valve was attached at the tank opening, while the other was used for bypass flow. The ball valve attached to the tank remains closed until steady flow has been achieved at the bypass flow. The flow meter was installed between the tank and the bypass valve. 


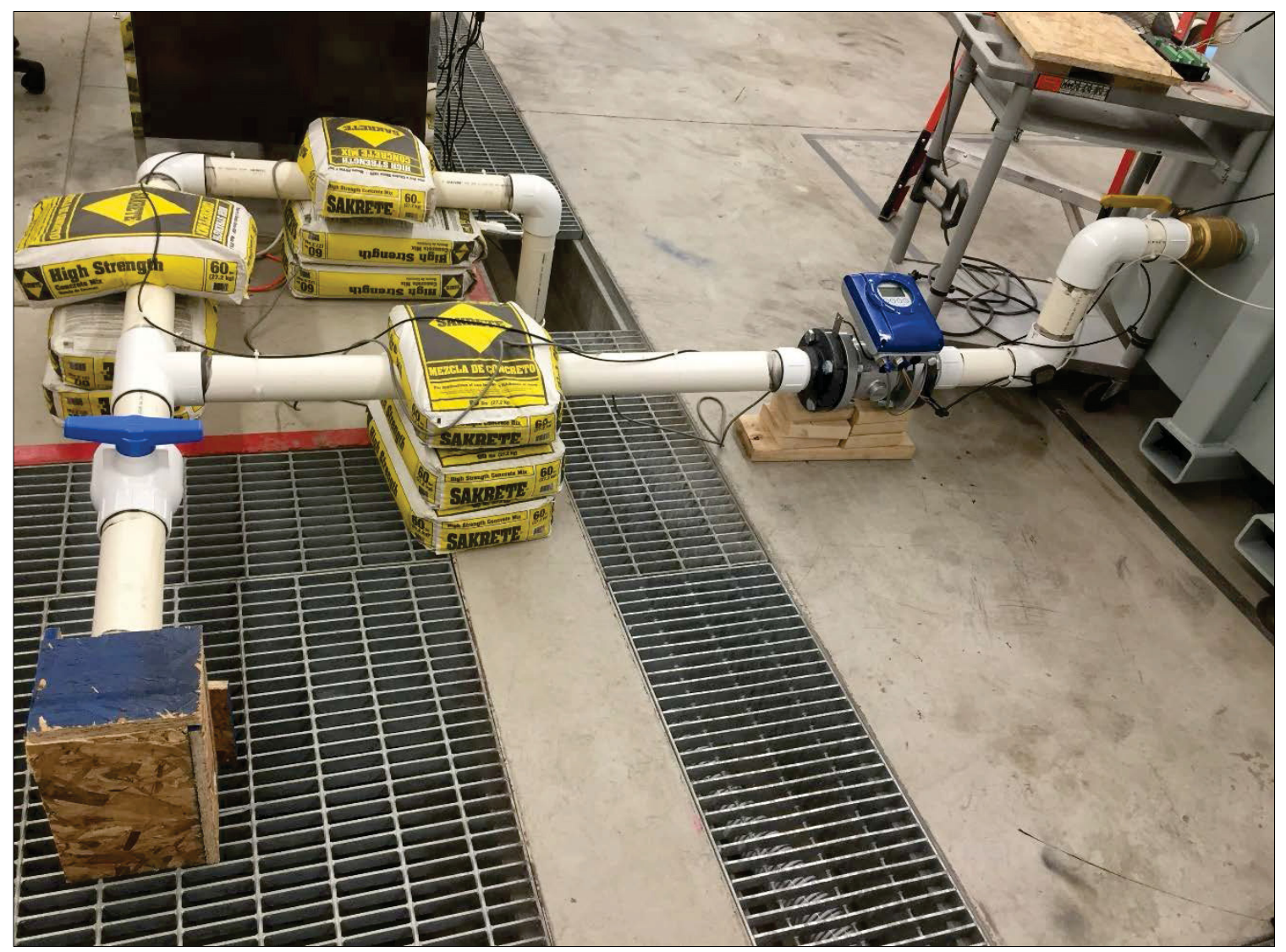

Figure 4. Piping, flow controls valves, and flow meter arrangement.

Four penetrations are located on the top of the PET as shown in Figure 5. An air relief valve, pressure relief valve, and pressure gauge were installed into three of the PET penetrations, and the fourth was used to insert the pressure transducer wire.

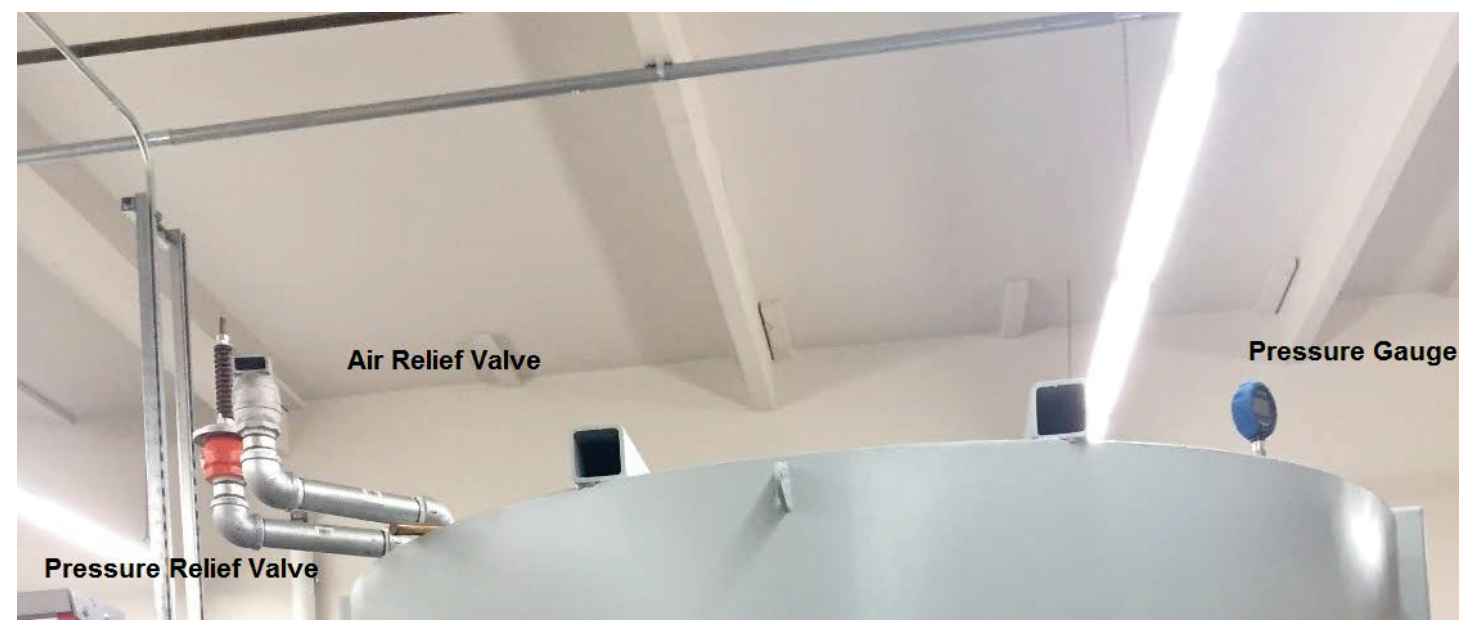

Figure 5. PET reliefs and pressure gauge.

\subsection{Experimental Setup}

The first series of experiments examined the behavior of full-scale interior doors subjected to a water rise scenario. The experiments provide the opportunity to acquire a deeper understanding of door failure modes as well as providing the opportunity to develop full-scale component testing protocol. 
The component selected for the initial experiments was a hollow 3-feet wide and 7-feet tall wood interior door. A door frame and wall were constructed to hang the door in the tank. The door frame and wall was constructed using 2 inch by 6 inch lumbers and plywood. Figure 6 shows the door frame under construction. The studs were placed 9 inches apart and double studs were used next to the door. The standard code for building frame uses studs with 16-inch spacing. The studs were placed 9 inches apart to strengthen the wall and ensure the door was the weakest component subjected to the water rise.

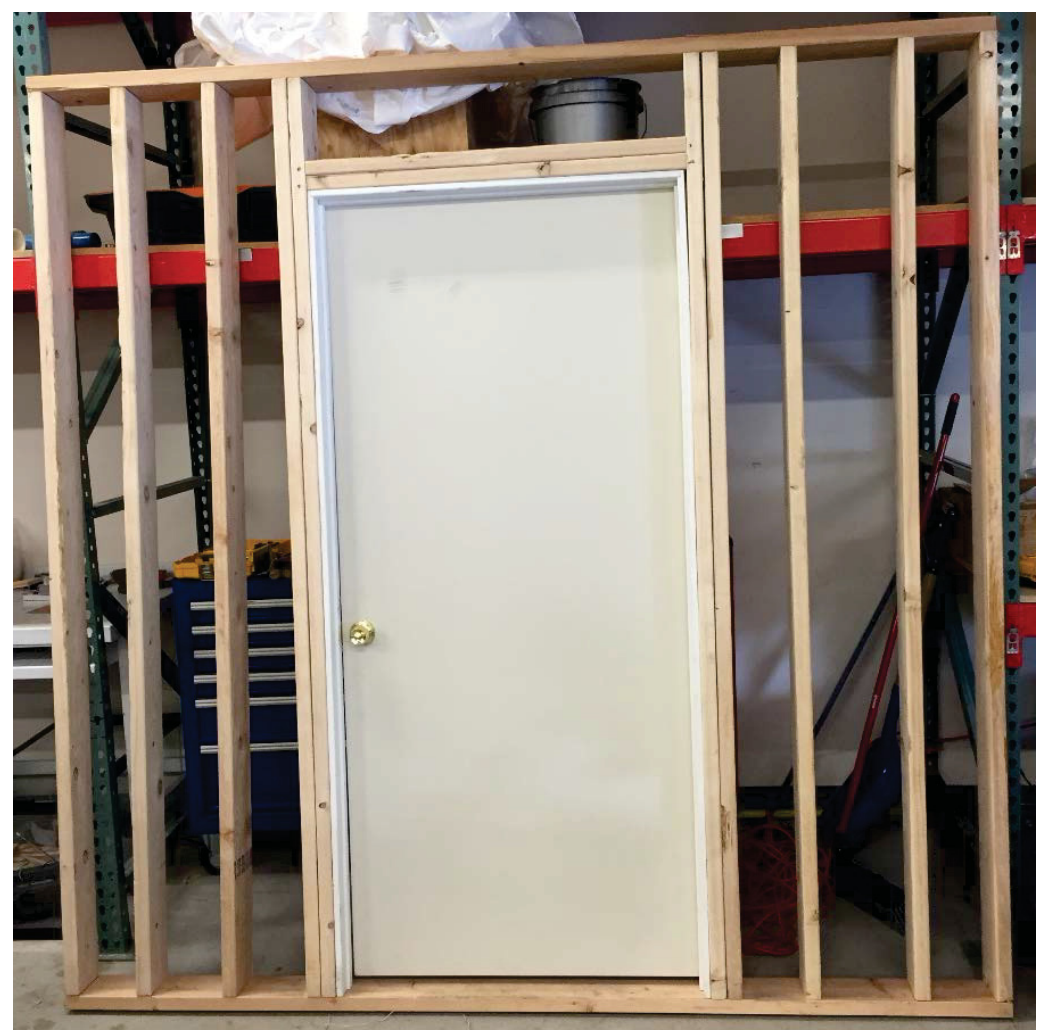

Figure 6. Wall frame and door assembly.

After construction of the wall assembly, it was installed in the tank. The wall assembly was screwed into angle iron welded to the tank assembly. Silicone and insulating foam were applied to prevent leakage. Additionally, the plywood portion of the wall was covered with seal paint to prevent water leakage.

The general approach of the experiment was to fill the tank with water until the door failed at a measured water height. Additionally, the door failure mode would be observed. The door is supported by hinges and the door latch mechanism. Since the door latch is only supported by two screws it was anticipated that failure would occur in this area.

\subsection{Testing Results}

\subsubsection{Experiment 1}

The first full-scale door experiment was performed June 27, 2016. In this experiment, the striker plate normally fastened to the door jamb where the latching mechanism engages the door frame was removed to allow investigation of only the wooden component of the frame. Figure 7 shows the pump flow rate for the experiment. The pressure transducer inside the tank measured the water depth as shown in Figure 8. 


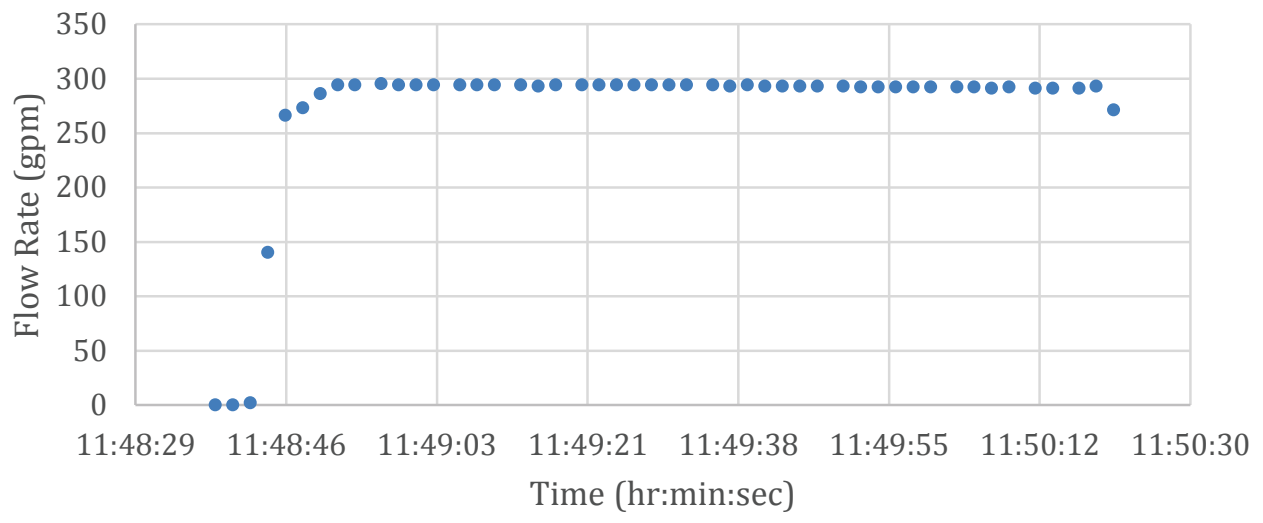

Figure 7. Initial experiment inlet flow rate.

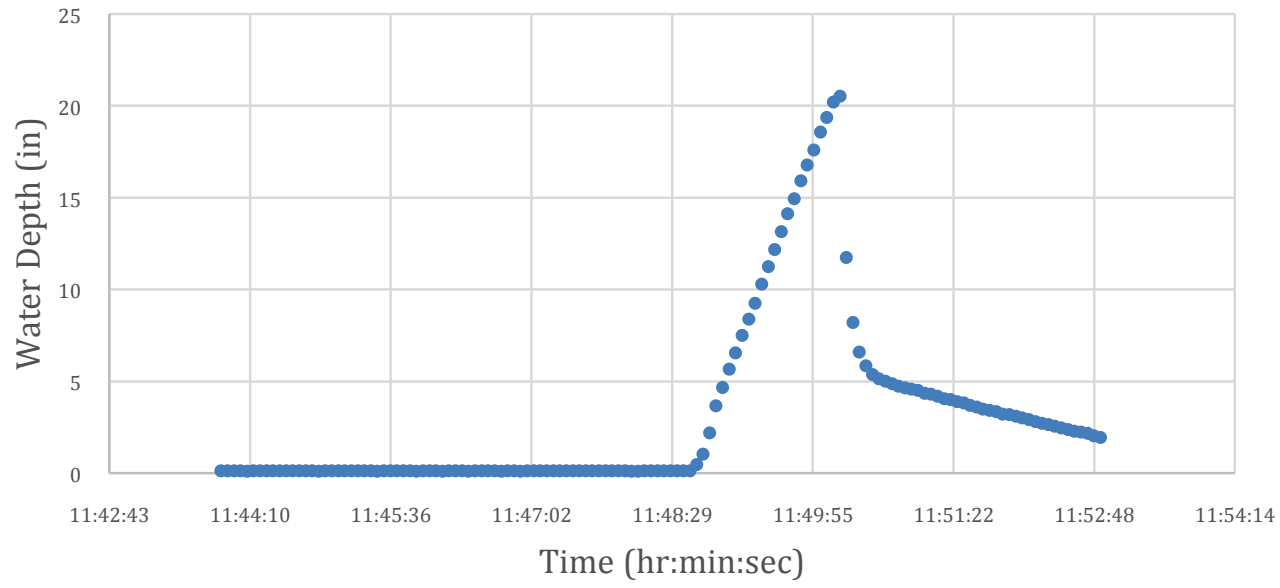

Figure 8. Water height inside the tank.

Failure occurred at approximately 11:50 am at a water depth of 21 inches. The wooden section of the door latch engagement area failed allowing the door to swing open. No damage to the door occurred; however, damage to the wooden piece on the door frame was apparent as shown in Figure 9. 


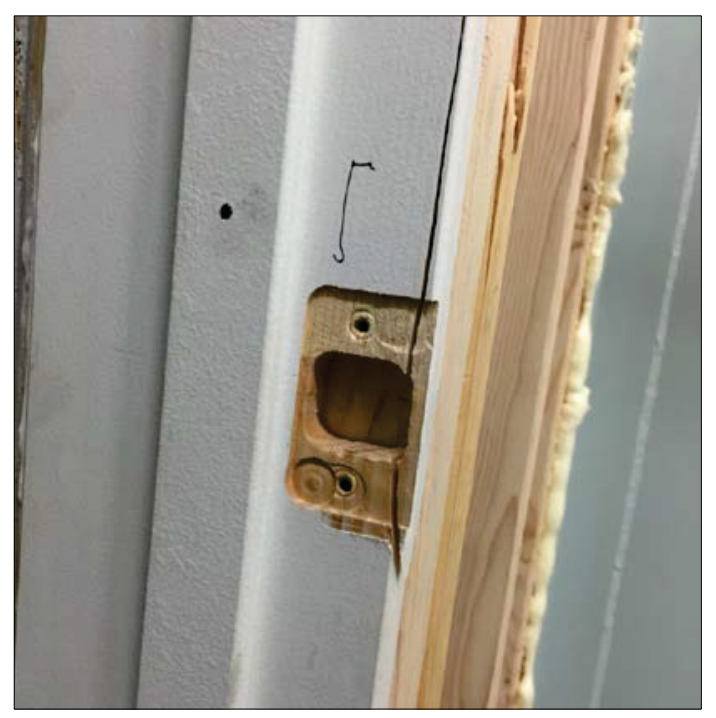

Figure 9. Experiment 1 door latch engagement area failure.

Data from the ultrasonic sensor was used with a weir flow rate equation to calculate the leakage flow. However, the leakage rate in this experiment overwhelmed the weir within the first few seconds of leakage flow at which point the ultrasonic depth measurements became meaningless as did the leakage flow rate calculations. Nonetheless, future experiments with smaller leakage flowrates will benefit from the ultrasonic level detector and weir.

\subsubsection{Experiment 2}

A second experiment was performed immediately following conclusion of the first. For this experiment, the metal bracket of the latch was installed, and the broken wooden section of the frame was glued back into place. To overcome excessive leakage identified in the first experiment, a plywood strap was attached at the bottom of the door and fastened to the studs around the door frame. The strap is not associated with a typical door arrangement, but was used to allow an experiment to proceed with greater water depths.

The pump was turned on at approximately 12:28 pm. The bypass flow valve remained open and the tank inlet remained closed until steady flow had been achieved. The inlet ball valve was then fully opened, the bypass ball valve fully closed, and water flowed into the tank at approximately 294 gpm.

At a flow rate of $294 \mathrm{gpm}$, the tank would fill in less than 10 minutes with no leakage. Figure 10 shows the water level inside the tank during the second experiment. Within 3 minutes, the water level had reached 40 inches. The water depth then remained fairly constant at 42 inches indicating that the overall leakage rate and inlet flow rate were essentially equal. After 3 minutes at this constant level, the lower portion of the door collapsed as shown in Figure 11 and the water in the tank was released. 


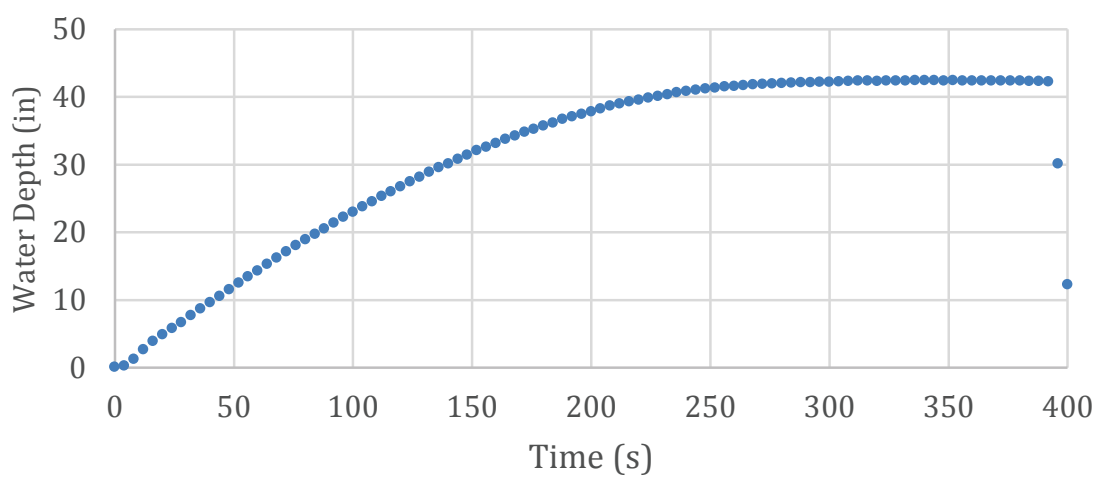

Figure 10. Experiment 2 tank water level.

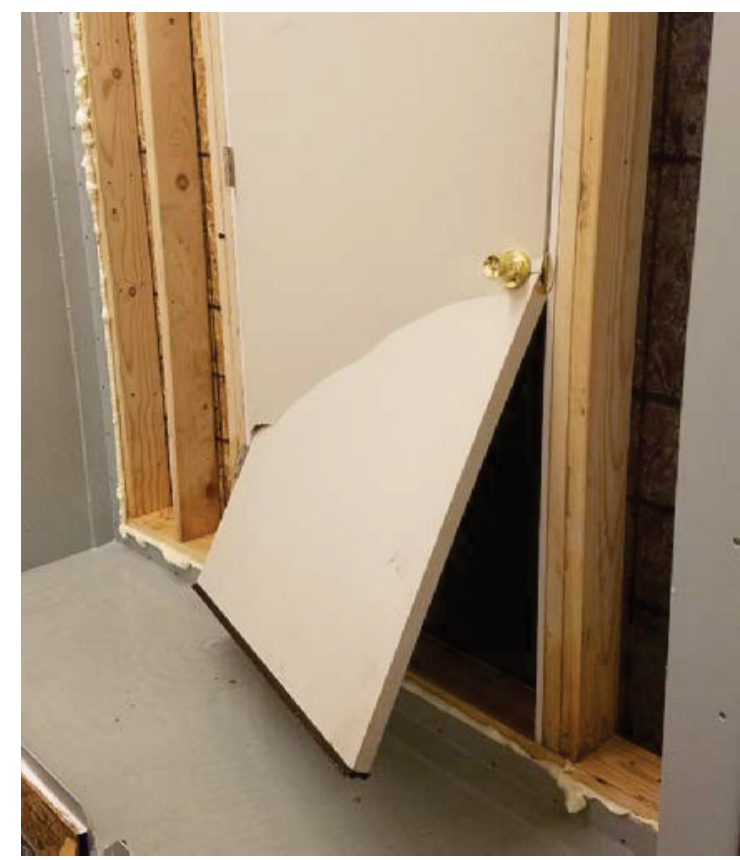

Figure 11. Experiment 2 door collapse. 


\subsubsection{Experiment 3}

The third experiment was performed July 18, 2016. Experimental parameters were repeated from the previous two experiments, with the door opening outwards. A strip of plywood was again attached to the frame across the bottom of the door to focus the experiment on equalization of inlet flow and leakage.

In this experiment, failure occurred at the connection between the door jamb and the striker plate. The door itself suffered no noticeable damage and was used again in later experiments. Figure 12 shows a front view of the progression of the door failure over the course of Experiment 3. In Figure 12 (a), the strip of plywood remains visibly attached to the bottom of the door. Figure 12 (c) shows fracturing at the door jamb as the door is forced open by water pressure. Lastly, the door is shown to be undamaged in Figure 12 (d); however, the strip of plywood has broken free of the screws holding it to the frame and is no longer visible. Figure 13 offers a top view of the progression.

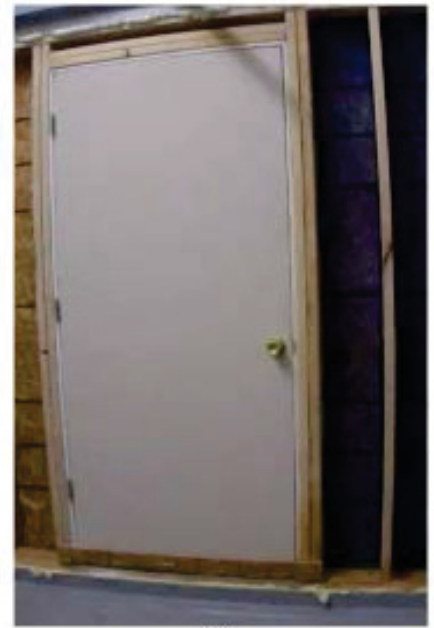

(a)

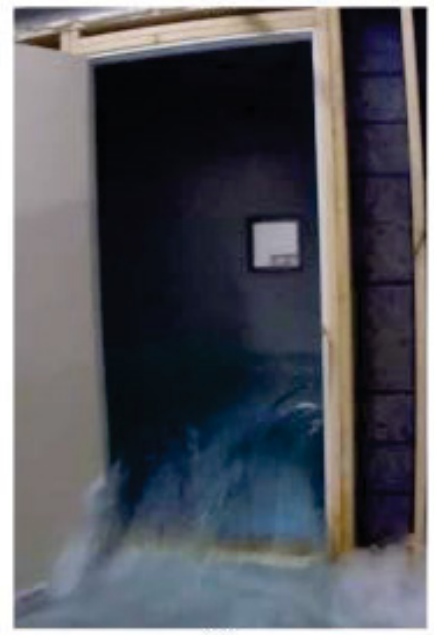

(c)

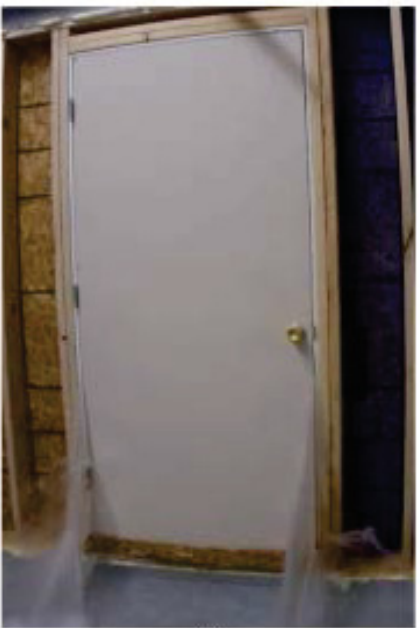

(b)

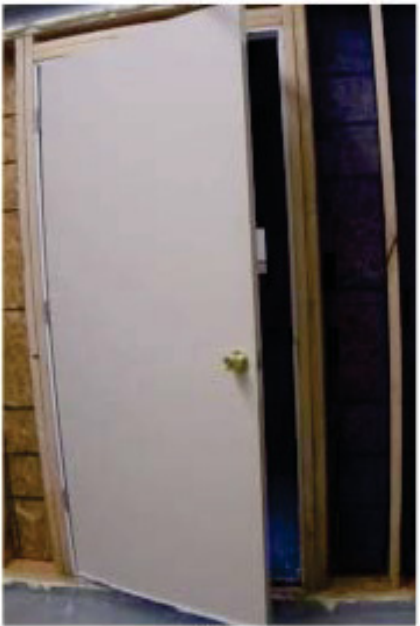

(d)

Figure 12. Experiment 3 progression. 


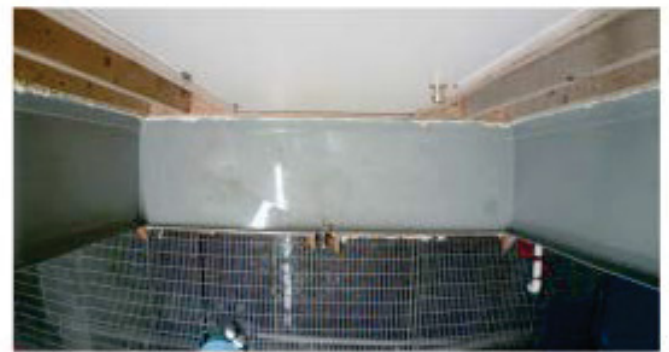

(a)

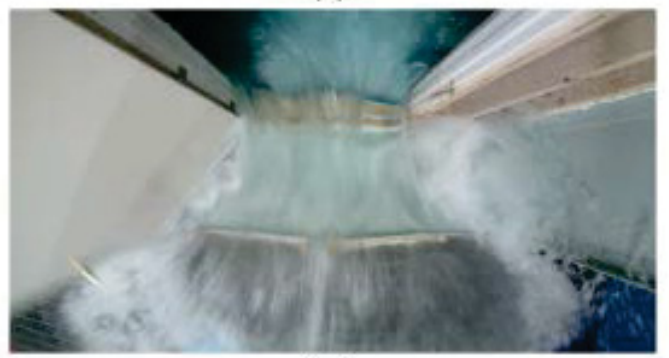

(c)

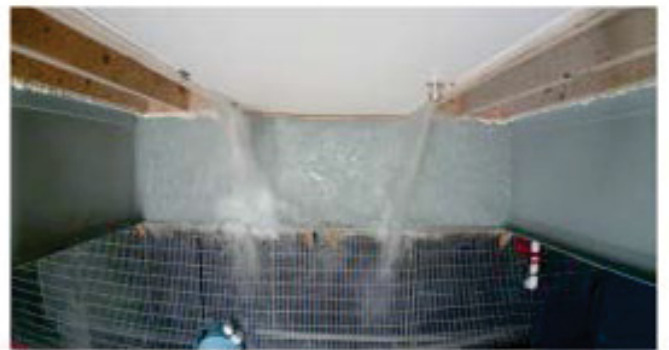

(b)

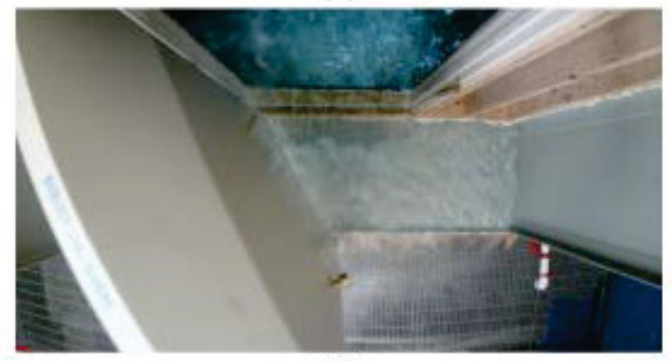

(d)

Figure 13. Experiment 3 top-view progression.

The inlet flow rate and fill rate data were used to calculate the leakage rate through the door. A plot of these calculated data can be found in Figure 14. It should be noted that calculations of the leakage rate assume an average flow rate into the tank. This was done to account for the difference in time resolution between the depth sensor and flow meter. The depth sensor has a resolution of 4 seconds, whereas the flow meter has a resolution that fluctuates between 2 and 3 seconds. The inlet flow rate is fairly consistent after initial startup; therefore, a constant flow rate was assumed. A slight decrease in flow rate of about 3\% was observed over the course of the entire experiment. This is likely due to changes in pump head, both upstream and downstream. Thus, Figure 14 provides trend information, but the actual data points require more analysis before they can be relied upon. These discoveries, along with the uncertainties for each measuring instrument, will be taken into account in future leak rate calculations. Figure 15 depicts the increase in water depth using measurements taken from the pressure transducer.

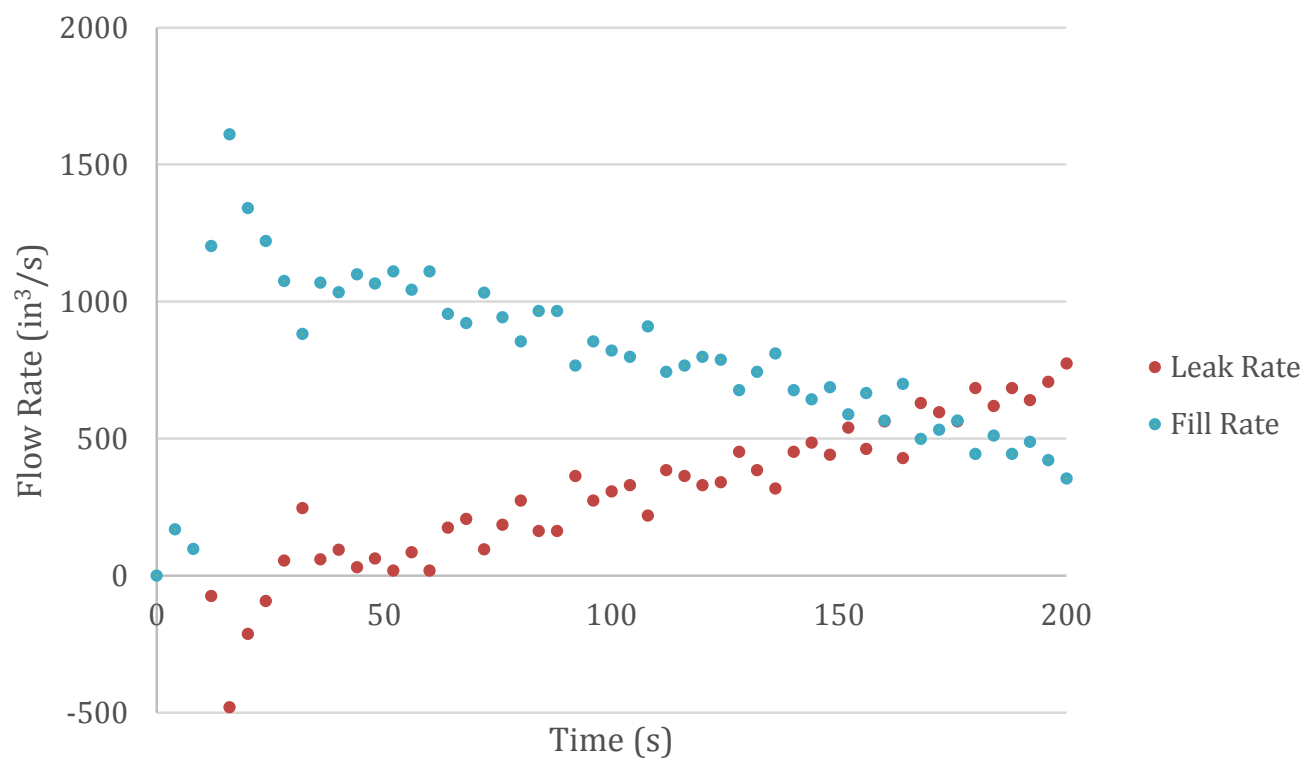

Figure 14. Experiment 3 Inlet flow rate, tank fill rate, and leakage rate. 


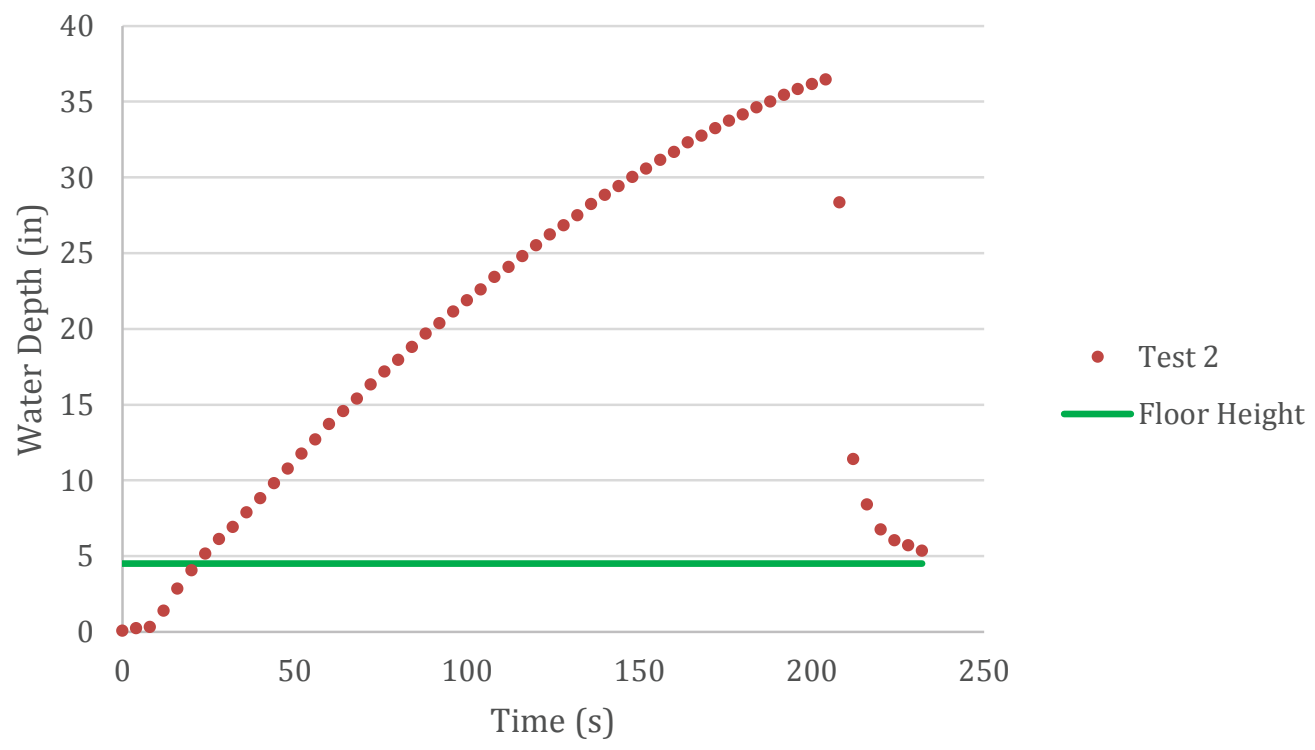

Figure 15. Experiment 3 tank water level.

\subsubsection{Experiment 4}

The fourth experiment took place August 2, 2016 and marked a significant change from the previous experiments. For this experiment, the door was installed to open inwardly toward the tank, whereas the first three experiments were conducted with the door opening outward. The water pressure would now force the door closed decreasing leakage, rather than forcing the door open increasing leakage.

Figure 16 shows the progression of door failure as seen from the front of the tank and Figure 17 shows this progression from above. The assumptions mentioned previously in Experiment 3 were also made in calculating and plotting the flow data shown in Figure 18 and the depth data shown in Figure 19. 


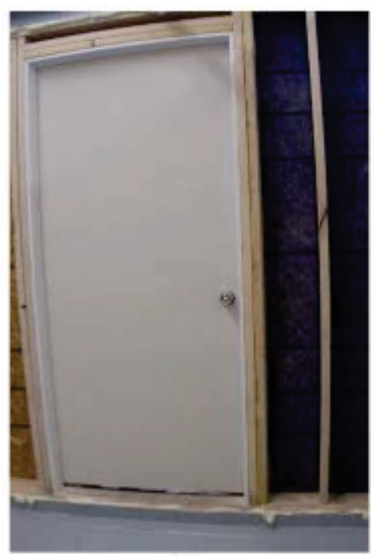

(a)

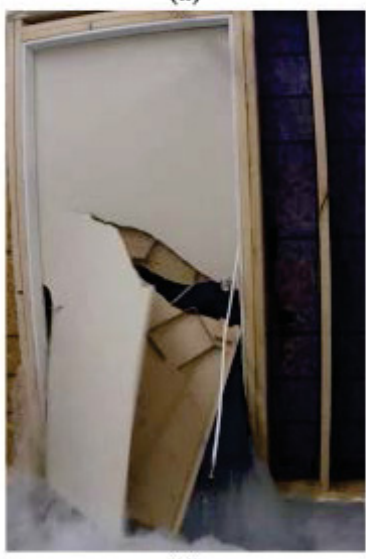

(c)

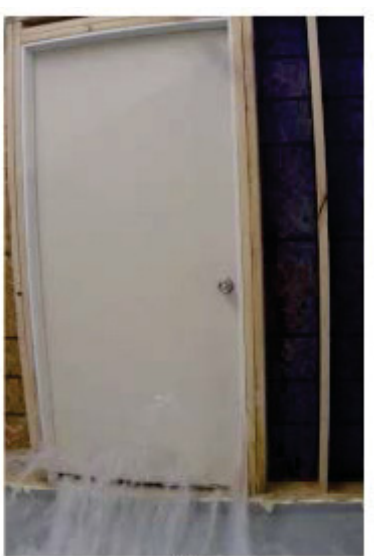

(b)

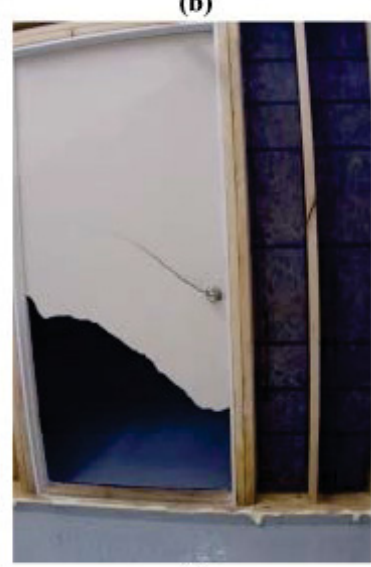

(d)

Figure 16. Experiment 4 failure progression.

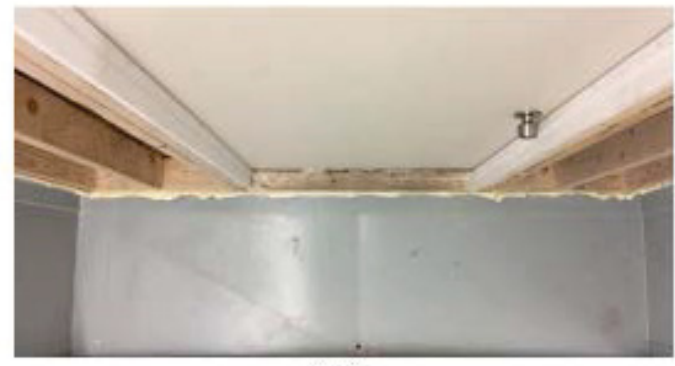

(a)

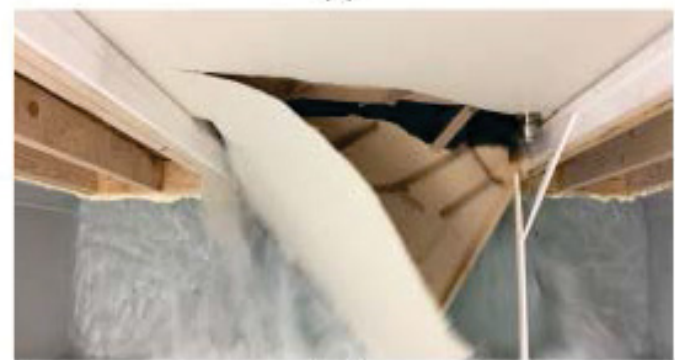

(c)

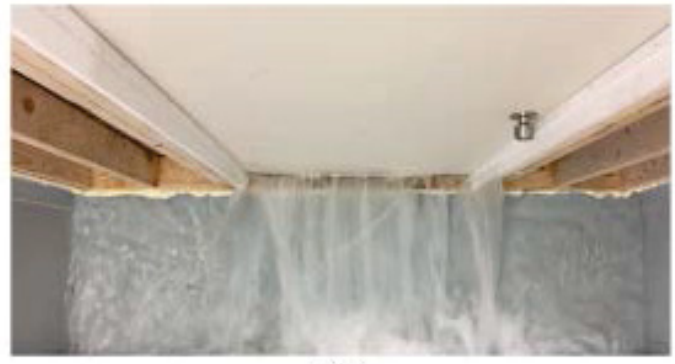

(b)

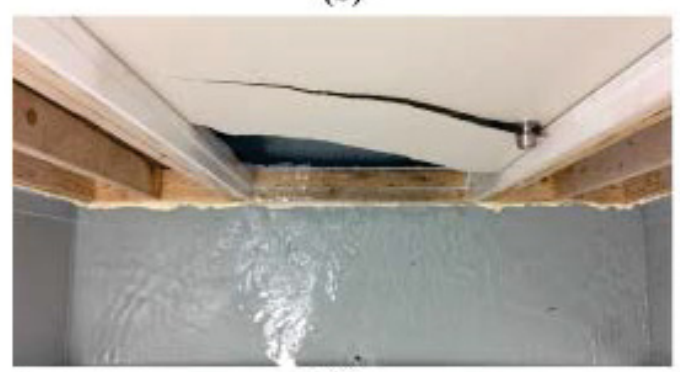

(d)

Figure 17. Experiment 4 failure progression, top view. 


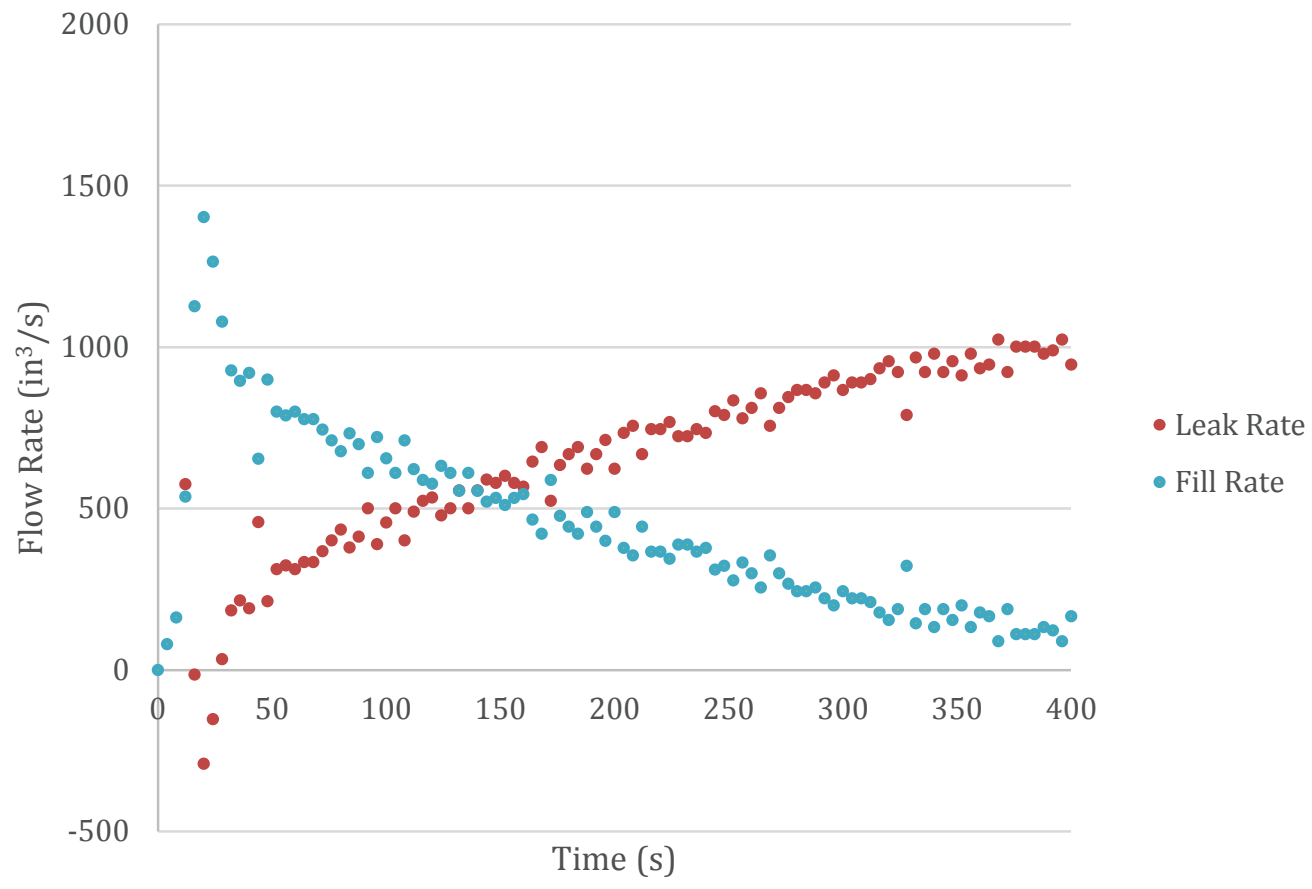

Figure 18. Experiment 4 inlet flow, fill rate, and leakage rate.

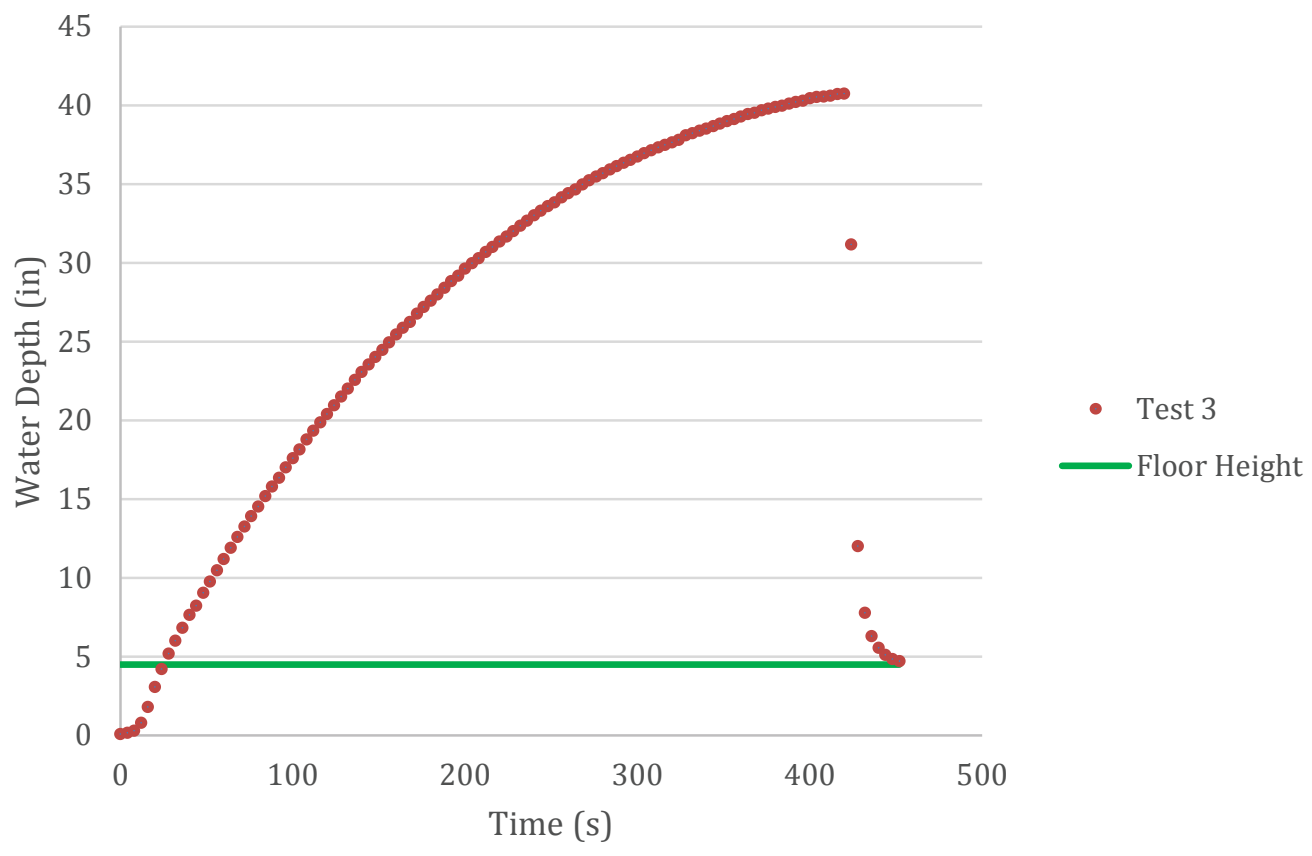

Figure 19. Experiment 4 water depth.

\subsubsection{Experiment 5}

The most recent experiment was performed on August 25, 2016. Similar to Experiment 4, the door was installed opening inward toward the tank. The main difference in this experiment was the in the construction of the door jamb. Rather than using a prefabricated jamb, this door jamb was constructed to accommodate an 
undamaged door previously used in Experiment 3. The jamb was built using a door jamb repair kit and materials equivalent to the other experiments. A new doorknob set was also installed.

Figure 20 shows the front view of the progression of failure (a top view was not recorded). Figure 21 shows the flow data, also using the assumptions stated in Experiment 3 and Figure 22 contains the depth data.

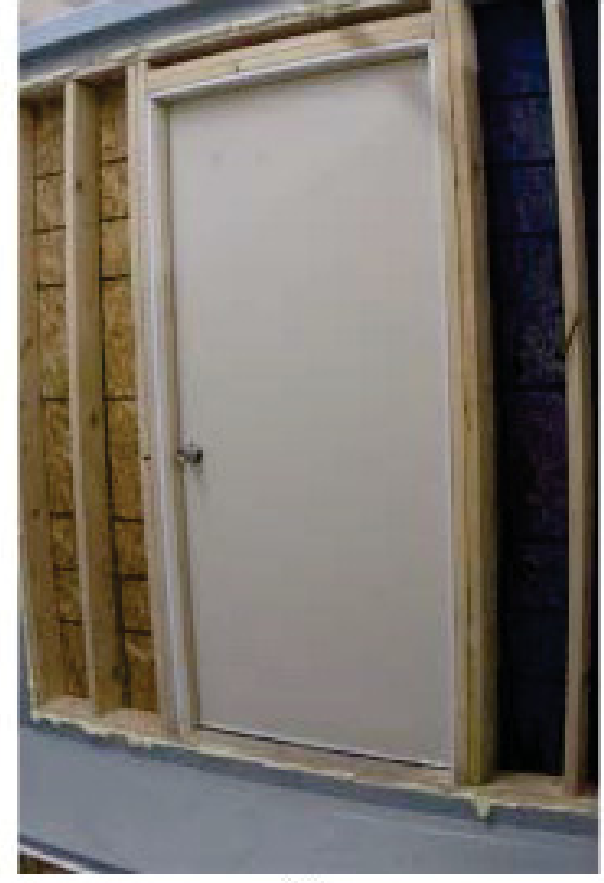

(a)

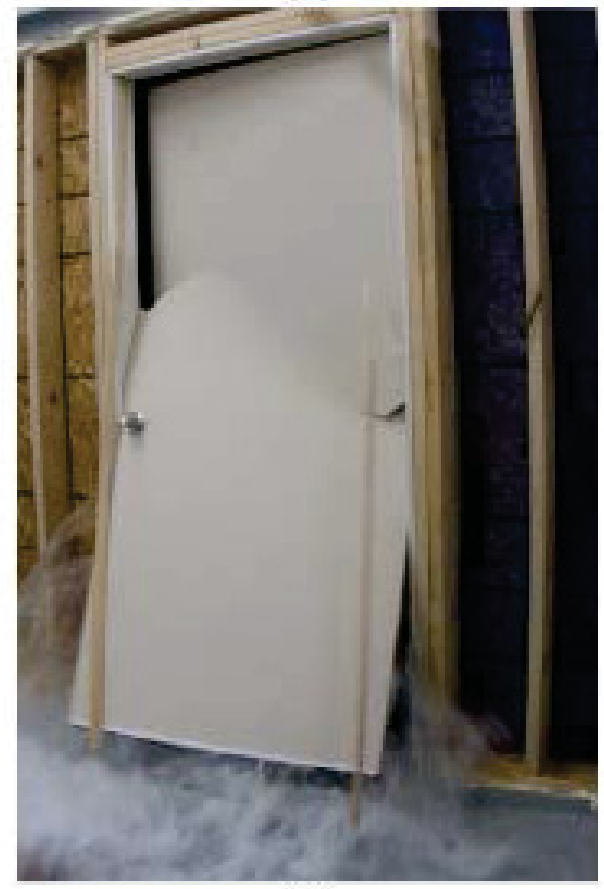

(c)

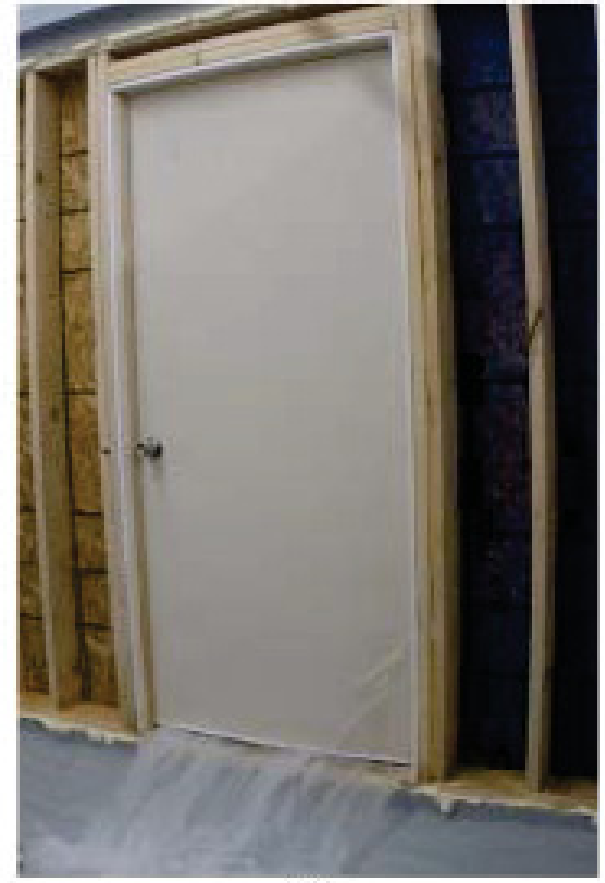

(b)

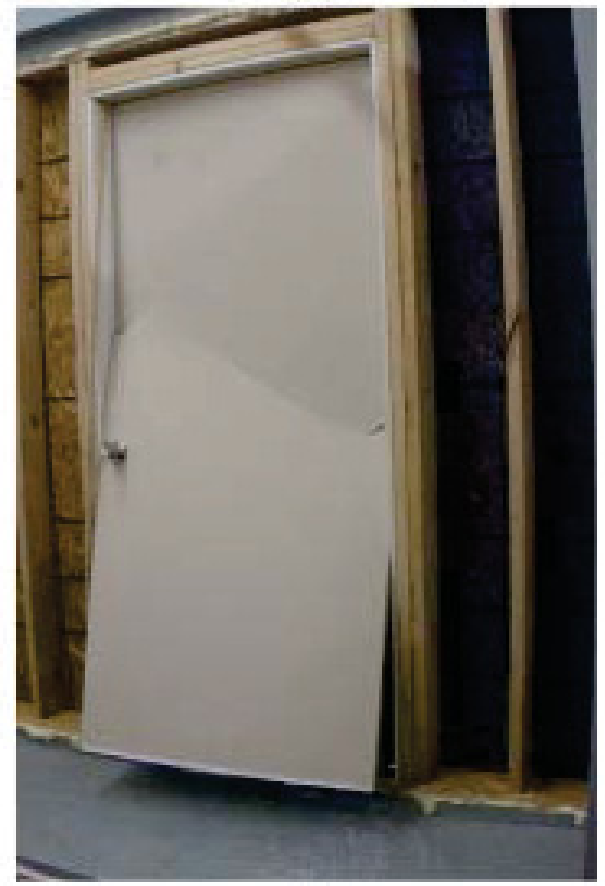

(d)

Figure 20. Experiment 5 failure progression. 


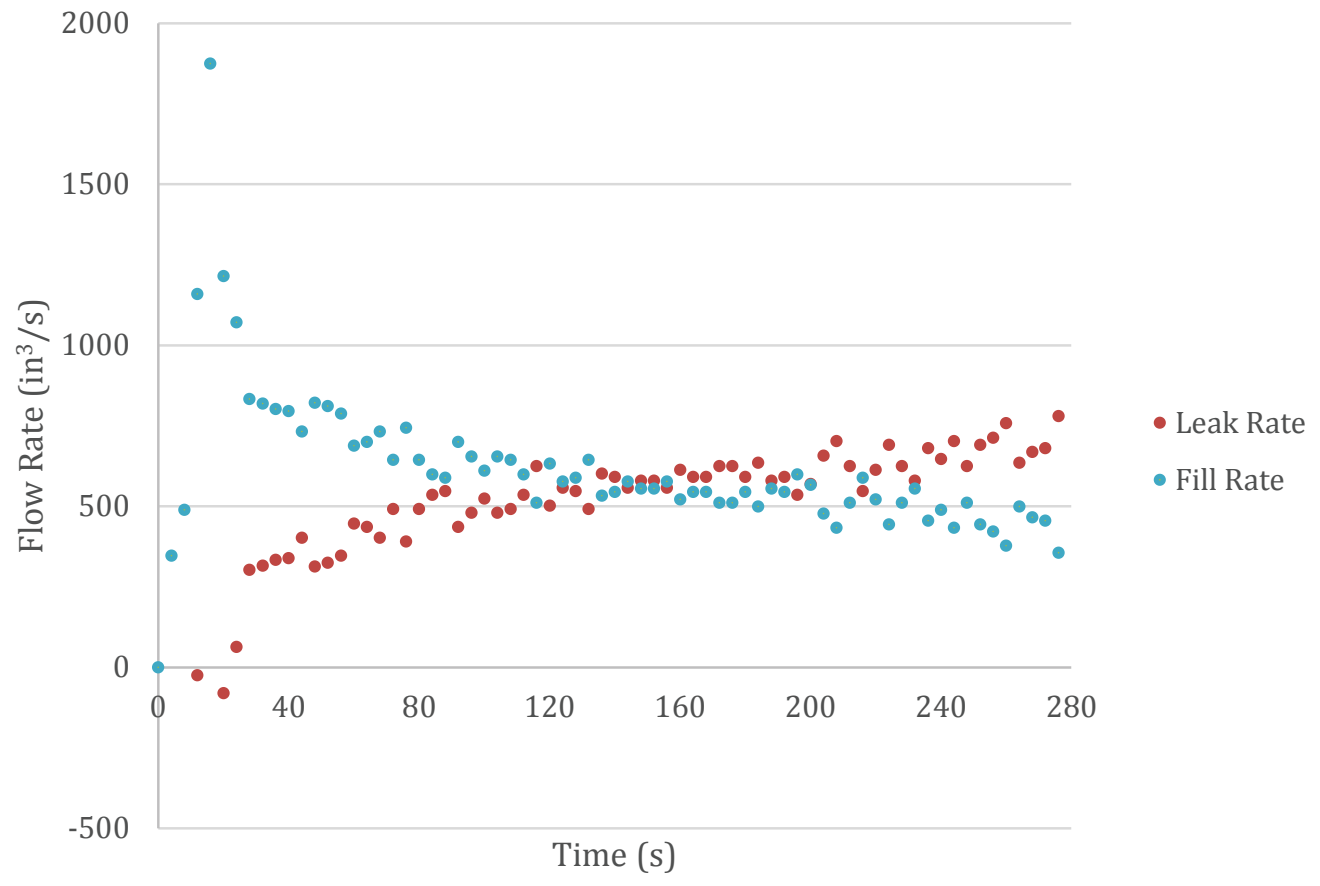

Figure 21. Experiment 5 inlet flow, fill rate, and leakage rate.

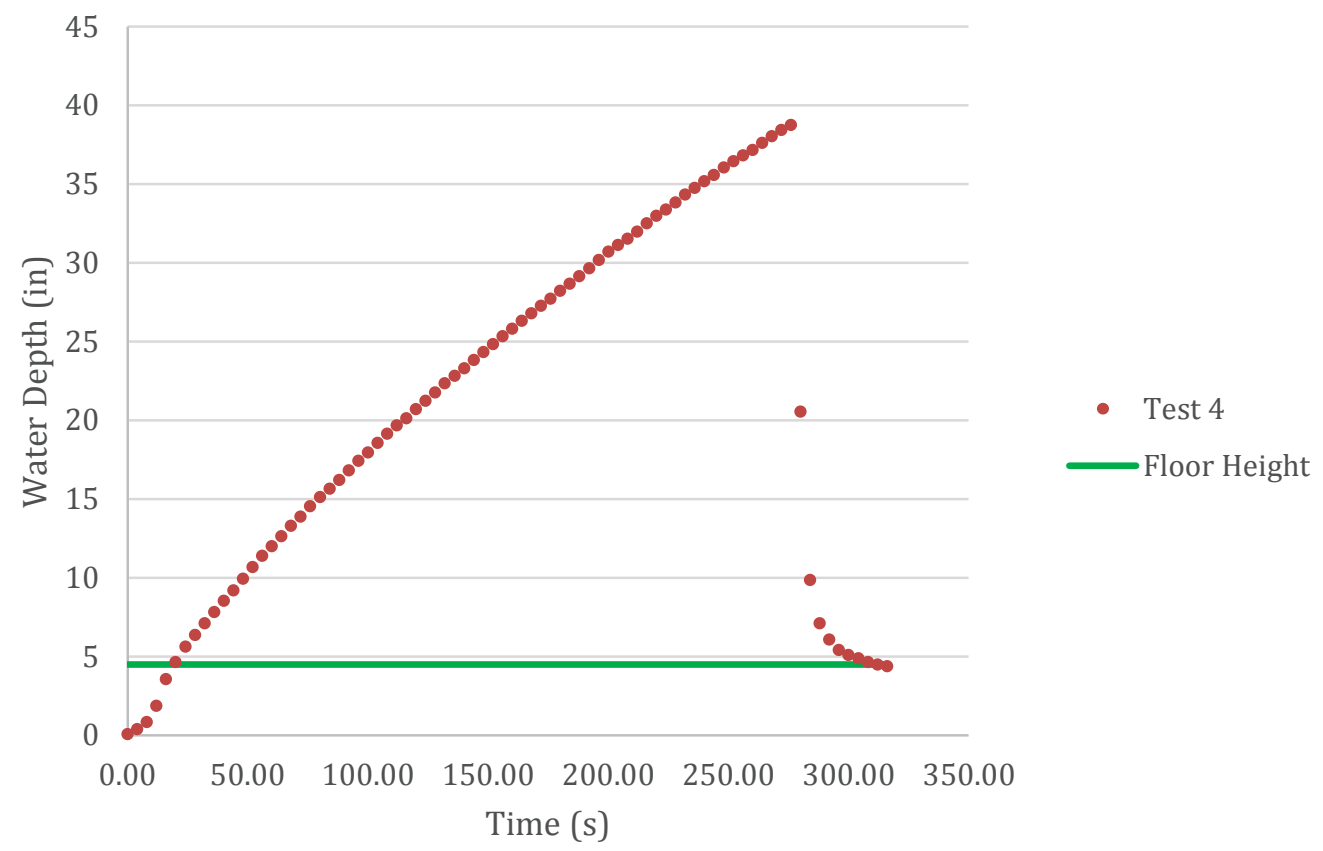

Figure 22. Experiment 5 water depth. 


\subsection{Flooding Fragility Experiments Conclusions}

The PET has been designed, constructed, and put into service. A series of five experiments using full-scale interior doors have been carried out. Results of these experiments have provided data that can be used for the development of Bayesian regression models. Additionally, the experiments have provided great insight into the process for conducting full-scale NPP component flooding experiments. Future experiments will focus on more representative components such as roll-up doors and metal doors. Additionally, given the modular design of the PET, experiments involving seals around wall penetration feedthroughs will be conducted. When these experiments are conducted, the leak rates should be sufficiently small that the ultrasonic level sensor and $\mathrm{V}$-notch weir will provide improved leak rate measurement. To ensure the leakage water is properly captured and measured at the weir, a plexiglass guard will be added to the PET so that leakage water cannot bypass the weir. 


\section{FLOODING FRAGILITY PROBABILISTIC MODELING}

The approach to use the flooding experimental data is through what are called fragility models. Historically, fragility models have been used primarily within the seismic community to represent the probability that a structure or component will fail as a function of the earthquake level. Typically, these fragility models have been simple monotonically-increasing functions that give the probability of failure of a single structure or component as a function of the earthquake severity as measured by a single metric such as the acceleration $(\mathrm{g})$ level. An example of what one of these seismic fragility models look like is shown in Figure 23.

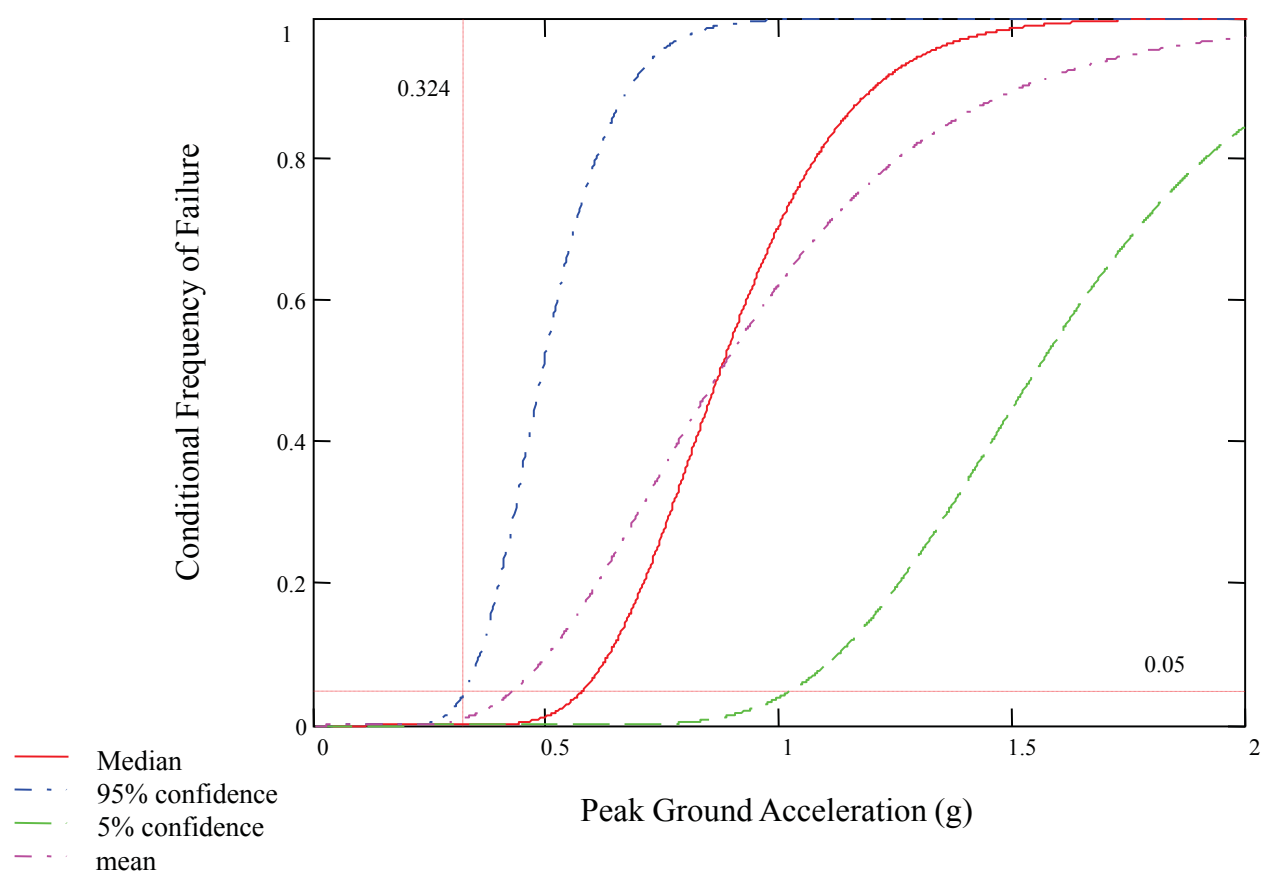

Figure 23. Illustration of seismic fragility model for an example component.

Limitations found in these traditional fragility models include: expert opinion, to simplistic (one single parameter), and excessive conservativism. For the flooding fragility modeling, we are attempting to avoid these issues by moving to a more flexible, data-informed approach - Bayesian fragility modeling through phenomenadriven regression modeling.

\subsection{Bayesian Fragility Modeling}

In the simple fragility models, a single parameter is used to completely characterize the failure probability, for example in seismic fragilities, the acceleration or "g," is used to determine the failure of the structure or component of interest. However, in reality, other observables may be better indicators for the potential of failures. For example, these observables could include the detailed characteristics of the earthquake such as the $\mathrm{X}, \mathrm{Y}$, and $\mathrm{Z}$ parts of the ground motion or the frequency of the wave; the age of the component; the anchorages of the component; or the specifics of the component type (or all of the above). Fortunately, there are advanced modeling techniques that are able to capture these types of modeling characteristics in a systematic and technically defensible fashion. 
Instead of a single "driving" parameter in a simple model, it is possible to represent affects by observable quantities such as energy level, age, inundation level, pressure, mass, temperature, etc., on the failure probability for a structure or component. For example, in the case of an engineered vessel, high pressure and temperature may be indicators of failures. We can use this information in a Bayesian inference approach to inform the fragility model for this vessel.

\subsection{Example of a Bayesian Regression Model}

Taken from Ref. [1], Table 1 shows data taken from the NASA Space Shuttle program related to O-ring impacts. Each shuttle had three primary and three secondary O-rings. The column labeled "distress" represents erosion or blow-by of an O-ring.

Table 1. O-ring thermal stress data prior to launch of Challenger in January 1986.

\begin{tabular}{llll}
\hline Flight & Distress & Temperature $\left({ }^{\circ} \mathrm{F}.\right)$ & Pressure $(\mathrm{psig})$ \\
\hline 1 & 0 & 66 & 50 \\
2 & 1 & 70 & 50 \\
3 & 0 & 69 & 50 \\
5 & 0 & 68 & 50 \\
6 & 0 & 67 & 50 \\
7 & 0 & 72 & 50 \\
8 & 0 & 73 & 100 \\
9 & 0 & 70 & 100 \\
$41-\mathrm{B}$ & 1 & 57 & 200 \\
$41-\mathrm{C}$ & 1 & 63 & 200 \\
$41-\mathrm{D}$ & 1 & 70 & 200 \\
$41-\mathrm{G}$ & 0 & 78 & 200 \\
$51-\mathrm{A}$ & 0 & 67 & 200 \\
$51-\mathrm{C}$ & 2 & 53 & 200 \\
$51-\mathrm{D}$ & 0 & 67 & 200 \\
$51-\mathrm{B}$ & 0 & 75 & 200 \\
$51-\mathrm{G}$ & 0 & 70 & 200 \\
$51-\mathrm{F}$ & 0 & 81 & 200 \\
$51-\mathrm{I}$ & 0 & 76 & 200 \\
$51-\mathrm{J}$ & 0 & 79 & 200 \\
$61-\mathrm{A}$ & 2 & 75 & 200 \\
$61-\mathrm{B}$ & 0 & 76 & 200 \\
$61-\mathrm{C}$ & 1 & 58 & 200 \\
\hline
\end{tabular}

There are two parts of this example required to carry out the quantitative modeling.

1. We need a model that represents the failure of an O-ring during a launch of the spacecraft. A commonly-used model for failures-on-demand is the binomial.

2. The key variable in the binomial model is the failure probability on demand, or $p$. However, for purposes of fragility modeling, we wish to determine what (if any) observable phenomena drive failures. Thus, we need to turn the parameter $p$ into its own model. 
For the Shuttle example, the primary failure model is binomial with parameters $p$ and $n=6$ (six O-rings are potentially challenged during each launch). In this model, $p$ is possibly a function of both temperature and applied pressure. One complication with the binomial model is that the parameter $p$ must be constrained between 0 and 1 since it represents a probability. A common approach to constrain this is to use the logit relationship for $p$ :

$$
\operatorname{logit}(p)=\ln \left(\frac{p}{1-p}\right)
$$

Our fragility model in this case will look at three possibilities, first that $p$ is determined by pressure and temperature, second that temperature alone drive failures, and third that pressure alone drive failures. These models are:

1. $\operatorname{logit}(p)=a+b T+c P$

2. $\operatorname{logit}(p)=a+b T$

3. $\operatorname{logit}(p)=a+c P$

To solve this example problem, we used the Bayesian tool called OpenBUGS. The OpenBUGS script for the first model in Equation (2), which includes both temperature and pressure, is shown in Table 2. Diffuse priors were used for the model parameters - if we had additional information related to these parameters we could include that information in the prior for each parameter. To solve the other fragility models shown in Equation (3) and (4), the script would be modified for the logit $(p)$ line.

\section{Table 2. OpenBUGS script for regression model for the O-ring fragility example.}

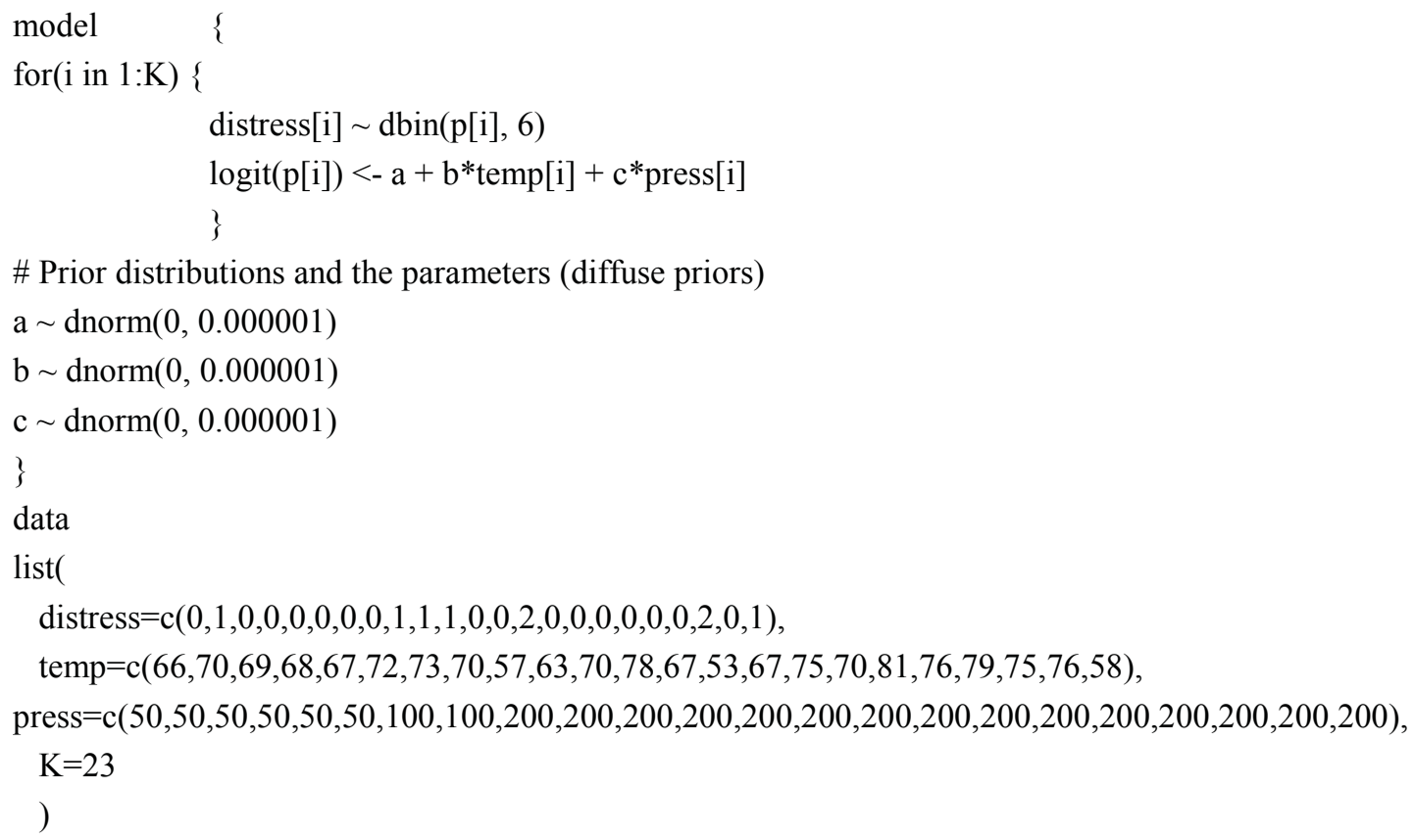

The results of running the script are shown in Table 3. In this table, we show the mean values calculated from OpenBUGS for the applicable parameters in the logistic regression fragility models. In addition to the 
parameter estimates, we show a Bayesian p-value for each model. This p-value metric can be used to determine model validity [1]. P-values closest to 0.5 indicate a high degree of predictive capability, which would indicate that Equation (4) (just a function of pressure) is slightly better than the other two models. However, these pvalues are all quite similar, and are not far from 0.5 , which suggests that they all perform adequately. We may choose to select Equation (2) in order to afford additional flexibility in case additional data is collected (which would not be possible in this case since the Shuttle program has ended) since we are not convinced the onlytemperature or the only-pressure cases are superior.

Table 3. Parameter results (mean values) of the O-ring fragility regression models.

\begin{tabular}{lccc}
\hline \multicolumn{1}{c}{ Parameter } & Equation 1 & Equation 2 & Equation 3 \\
\hline$a$ (intercept) & 2.1 & 5.2 & -5.0 \\
$b$ (temperature coefficient) & -0.10 & -0.12 & $\mathrm{n} / \mathrm{a}$ \\
$c$ (pressure coefficient) & 0.012 & $\mathrm{n} / \mathrm{a}$ & 0.013 \\
Bayesian p-value & 0.19 & 0.21 & 0.26 \\
\hline
\end{tabular}

The parameters in the table can be used with the fragility model to calculate the failure probability $p$ for an O-ring as a function of pressure and temperature. For example, using the Equation (2) fragility model, we can determine:

$p=\frac{1}{e^{-(a+b T+c P)}+1}$

Plotting the three fragility models provides the results shown in Figure 24 . Note that the fragility model given by Equation (4) is invariant to changes in the temperature ( $p$ stays at 0.024 ) since the regression model in that case had the temperature parameter removed from the model. Further note that the uncertainty on these results are not shown for clarity, but the full uncertainty on the fragility model could be determined since the uncertainty on all of the parameters are quantified via OpenBUGS. 


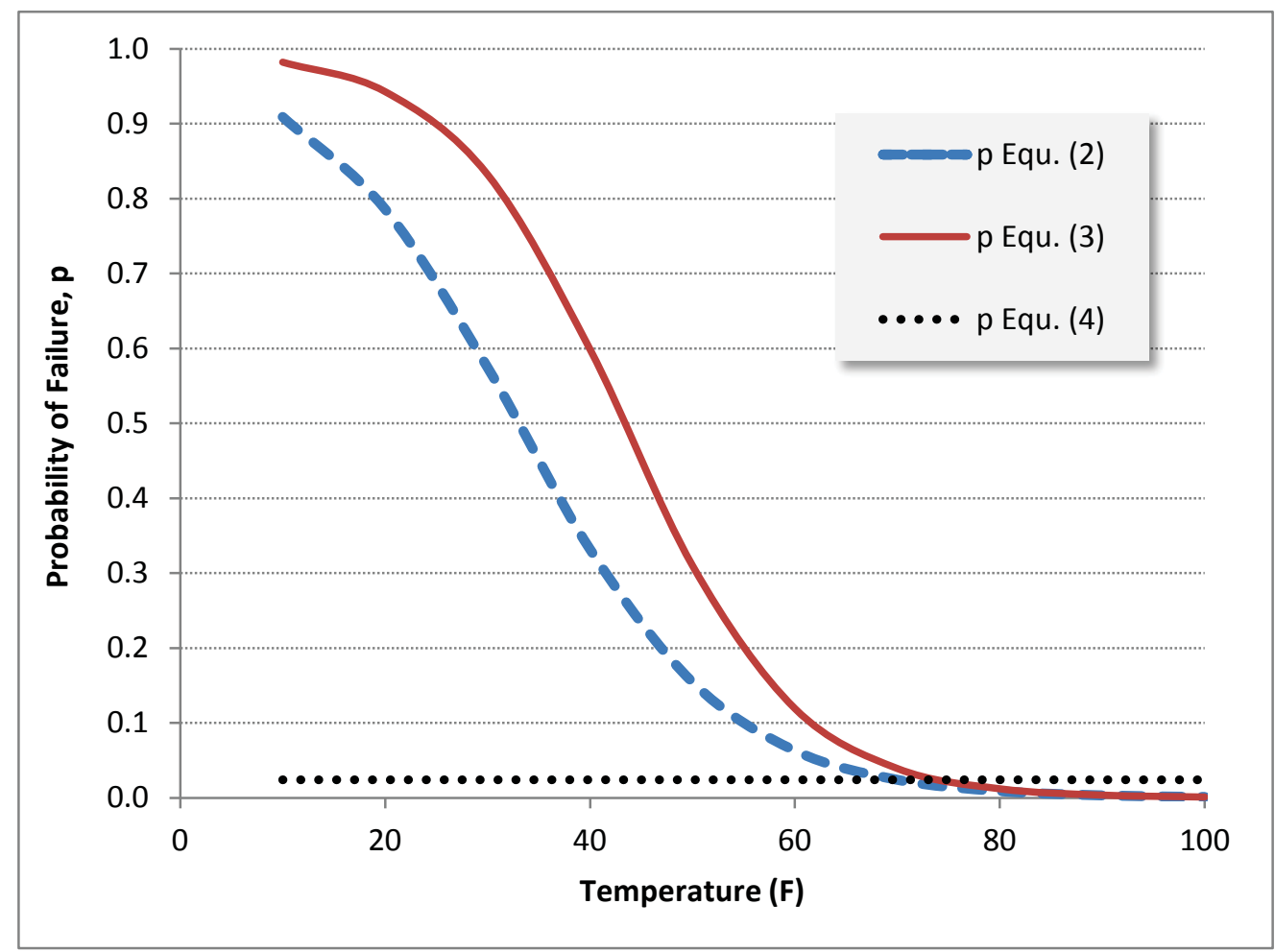

Figure 24. Fragility model results for the O-ring example.

\subsection{Example of a Flooding Bayesian Regression Model}

The bulk of fragility modeling in the nuclear industry has been focused on seismic component fragility determination. This (mostly) works by shaking components (e.g., simulating a "g" level earthquake) to find the point where components fail. For flooding fragility, a simple one-dimensional fragility model may be adequate for some flooding types (e.g., submersion depth for a slow-rising flood) and components, but other flooding scenarios (e.g., waves, spray) may require a more complicated regression fragility model to capture the phenomena adequately. An example of the testing results for a submersion-type of experiment is shown in Figure 25 where a component is tested to failure from rising water. 


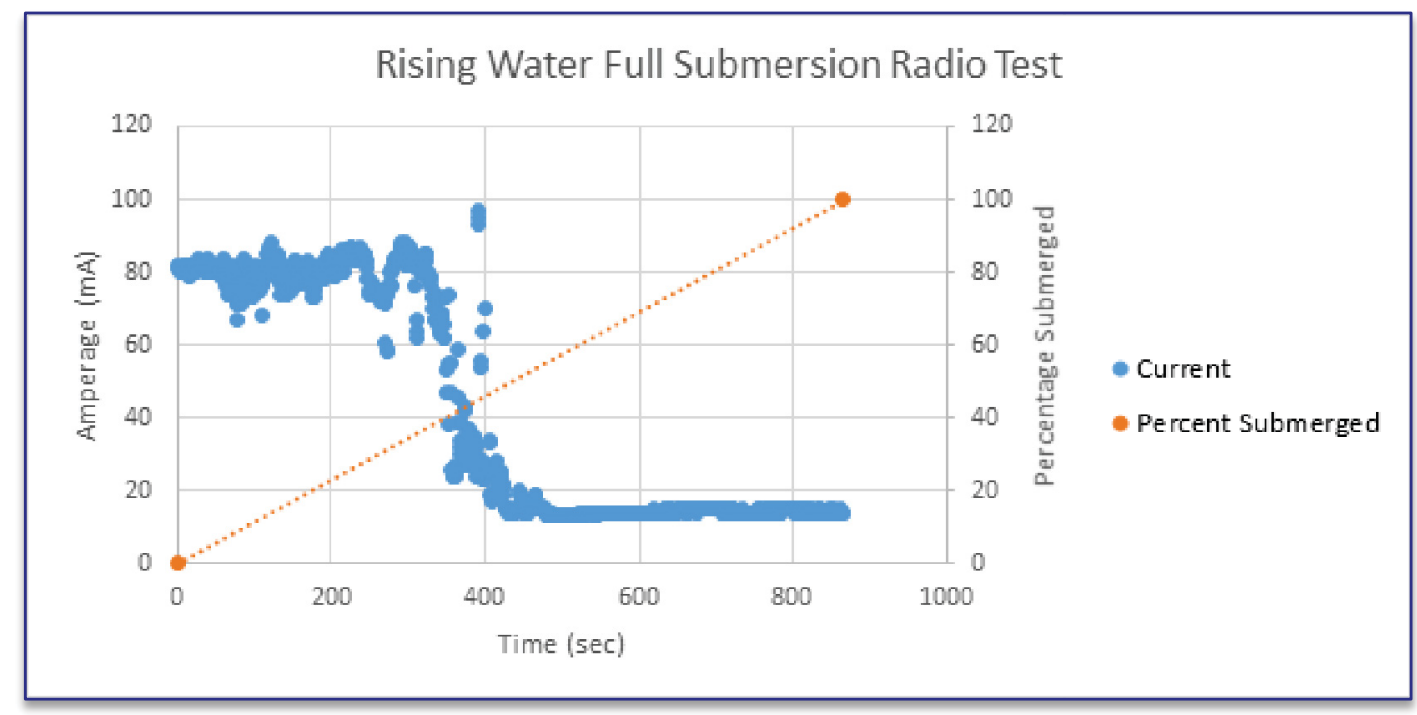

Figure 25. Illustration of the type of information collected during flooding fragility testing.

One of the complications for flooding fragility modeling is in the variety of observable phenomena related to the flood itself. Figure 26 shows some of the possible influencing factors that could be present when considering flooding fragility models. When constructing these types of regression-based models, some thought should be given to which factors might be most important. However, one of the advantages of a Bayesian quantification approach is that for those factors that do not play an important role, the parameters in the regression model associated with the unimportant factors should be found to be negligible. We will demonstrate this behavior in this section.

For the second example, let us assume that we have a component that has the potential for three floodingrelated influencing factors leading to failure; we will label these $\mathrm{A}, \mathrm{B}$, and $\mathrm{C}$ (these could represent water height, water impact pressure, and component type, for example). The "model" for these factors are chosen to be:

$\mathrm{A} \rightarrow$ normal distribution with mean of 0.5 and standard deviation of 0.1

$\mathrm{B} \rightarrow$ normal distribution with mean of 0.5 and standard deviation of 0.1 (and independent of $\mathrm{A}$ )

$\mathrm{C} \rightarrow$ uniform distribution between 0 and 1 (and independent of $\mathrm{A}$ and $\mathrm{B}$ )

We will then assume a failure criterion of

- Failure if either $\mathrm{A}>0.55$ or $\mathrm{B}>0.55$

- Success otherwise

By having these assumed failure models and failure criterion, we can create synthetic data (via simulation) and use that data in a Bayesian regression model to see if we are able to determine the known (in this example) conditions for failure. For example, since the model for $\mathrm{C}$ has no effect on failures or successes, it should turn out that this parameter has no influence on the fragility model prediction. 


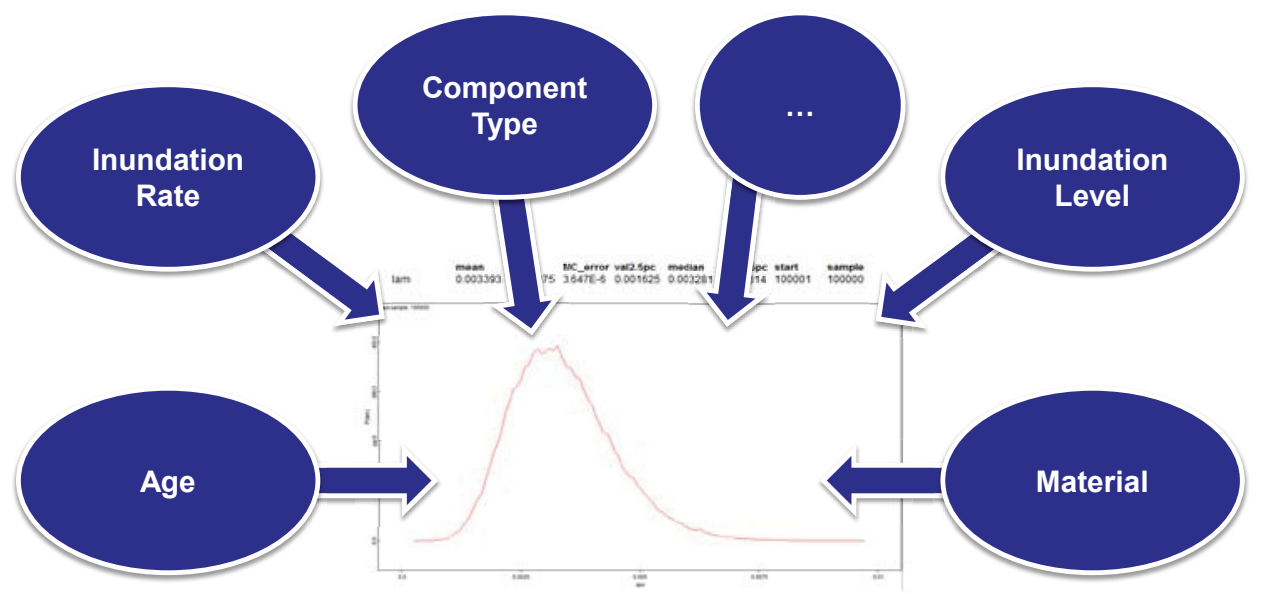

Figure 26. Example of possible influencing factors that may affect component flooding fragility.

An example of the simulated data is shown in Table 4 (created by sampling the three "models" for A, B, and $\mathrm{C}$ and testing against the failure criteria). For this example, we used the fragility model of:

$$
\operatorname{logit}(p)=\text { intercept }+a \mathrm{~A}+b \mathrm{~B}+c \mathrm{C}
$$

Table 4. Simulated flooding failure data.

\begin{tabular}{|c|c|c|c|c|}
\hline Test \# & A & B & C & $\begin{array}{c}\text { Failure? } \\
(0=\text { no, } 1=\text { yes })\end{array}$ \\
\hline 1 & 0.52 & 0.56 & 0.89 & 1 \\
\hline 2 & 0.53 & 0.45 & 0.03 & 0 \\
\hline 3 & 0.58 & 0.53 & 0.34 & 1 \\
\hline 4 & 0.64 & 0.50 & 0.24 & 1 \\
\hline 5 & 0.39 & 0.52 & 0.02 & 0 \\
\hline 6 & 0.45 & 0.43 & 0.39 & 0 \\
\hline 7 & 0.50 & 0.50 & 0.48 & 0 \\
\hline 8 & 0.59 & 0.38 & 0.96 & 1 \\
\hline 9 & 0.52 & 0.54 & 0.68 & 0 \\
\hline 10 & 0.50 & 0.52 & 0.63 & 0 \\
\hline 11 & 0.51 & 0.43 & 0.57 & 0 \\
\hline 12 & 0.45 & 0.48 & 0.66 & 0 \\
\hline 13 & 0.42 & 0.52 & 0.02 & 0 \\
\hline 14 & 0.43 & 0.62 & 0.13 & 1 \\
\hline 15 & 0.60 & 0.52 & 0.97 & 1 \\
\hline
\end{tabular}

The script to run this example is shown in Table 5. The results of the OpenBUGS analysis, mean value of each parameter, are listed in Table 6. 
Table 5. OpenBUGS script for flooding fragility model for the synthetic example.

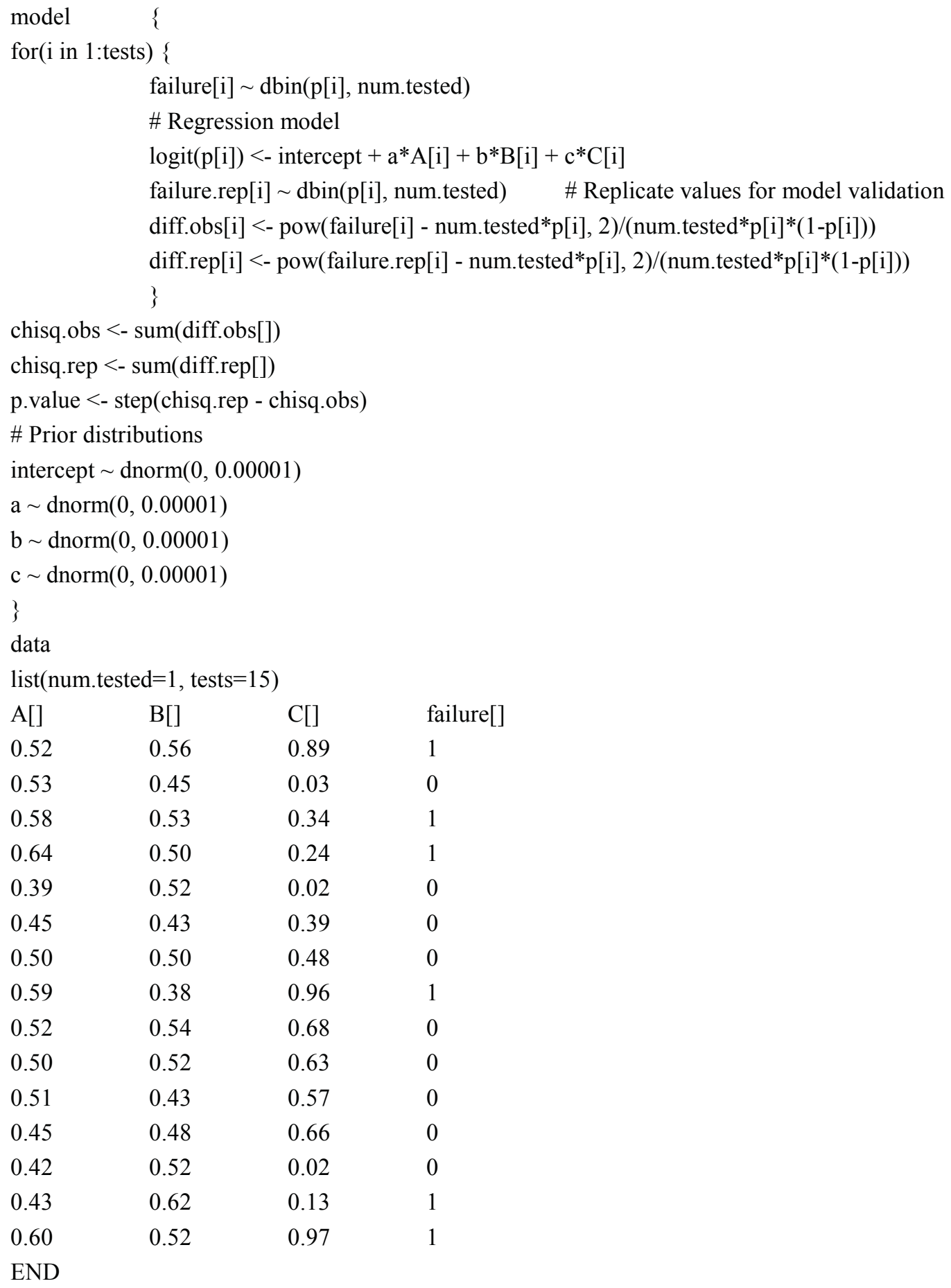

$\begin{array}{llll}0.50 & 0.52 & 0.63 & 0\end{array}$

$\begin{array}{llll}0.51 & 0.43 & 0.57 & 0\end{array}$

$\begin{array}{llll}0.45 & 0.48 & 0.66 & 0\end{array}$

$\begin{array}{llll}0.42 & 0.52 & 0.02 & 0\end{array}$

$\begin{array}{llll}0.43 & 0.62 & 0.13 & 1\end{array}$

$\begin{array}{llll}0.60 & 0.52 & 0.97 & 1\end{array}$

END 
Table 6. Parameter results (mean values) of the fragility model for the synthetic example.

\begin{tabular}{ll}
\hline \multicolumn{1}{c}{ Parameter } & Mean Value \\
\hline Intercept & -60 \\
$a$ & 71 \\
$b$ & 45 \\
$c$ & 0.54 \\
Bayesian p-value & 0.10 \\
\hline
\end{tabular}

As can be seen in Table 6, the impact of the $\mathrm{C}$ influencing factor is negligible compared to $\mathrm{A}$ and $\mathrm{B}$. The overall results of the fragility model can be seen in Figure 27 where we kept $C=0.5$ and varied the $A$ influencing factor for different levels of the B influencing factor. A couple of observations arise from these results:

- As B increases, the likelihood of failure of the hypothetical component increase since our known failure criteria is failure happens when A or B is larger than 0.55 .

- Failures are not predicted at low levels of A or B, even for the cases where B was set to a value larger than 0.55 . For example, in the case where $\mathrm{B}=0.7$, the predicted failure probability from the fragility model is approximately zero until A approaches 0.3 to 0.4 . The reason for this is that we created the influencing factors such that they were centered on an "impact factor" of 0.5 and dropped off rapidly (due to the normal distribution model) - consequently we did not see any failures where B was large (greater than 0.55) and A was very low (less than 0.3). This is an example where correlations exist in the model, but these correlations are automatically built into the Bayesian model and are treated appropriately by OpenBUGS.

- While not shown, changing the $\mathrm{C}$ influencing factor had a negligible change in the fragility probability. The influence of this factor is approximately 100 times less than the impact of A or B. One may ask why does $\mathrm{C}$ have any impact, and the answer is that the Bayesian model is probabilistic and, as such, it accounts for possibilities. It is possible that $\mathrm{C}$ plays a role, but in this case, the results indicate that it is just not likely.

- Even though we set up the synthetic model such that A and B have equal influence, the analysis seems to indicate $A$ is a more important driver of failure compared to $B(a=71$ versus $b=45)$. The reason for this is that during the synthetic data production, we saw four failures due to A versus two failures due to B. This behavior is a stochastic result - as additional failures are collected, this difference will tend to be minimized.

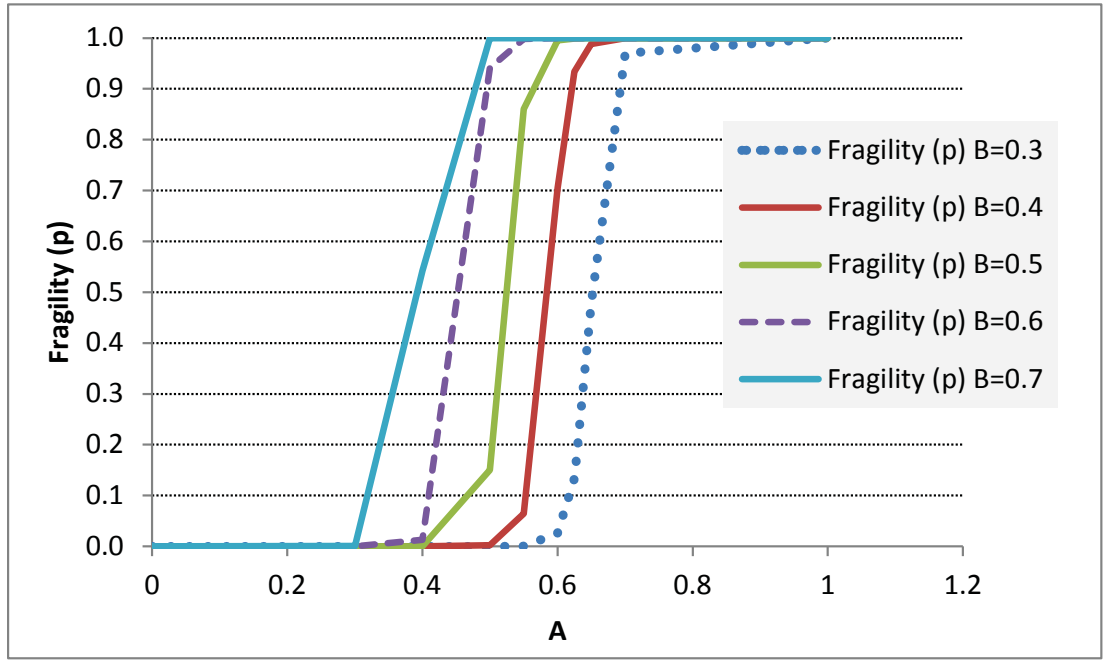

Figure 27. Results of the synthetic flooding fragility example. 


\section{CONCLUSIONS}

Bayesian estimation of the parameters in regression models has been challenging in the past - however with the availability of modern software and computers, these calculations are straightforward and tractable. Further, the Bayesian approach allows for a quantitative assessment of both the uncertainties in the models and their validity (through model checking). We have demonstrated that a Bayesian regression model can be used to determine the fragility (i.e., the probability of failure) for a component that is a function of complex, observable impacts such as water height, water pressure, spray rate, spray direction, component type, etc. This analysis approach complements the experimental data collection that is taking place related to flooding fragility for structures and components within the RISMC Pathway. 


\section{REFERENCES}

[1] D. Kelly and C. Smith, Bayesian Inference for Probabilistic Risk Assessment, Springer, 2011. 